JOSÉ LUIZ SOUZA DE MORAES

\title{
A ordem pública no direito internacional privado da família: parâmetros constitucionais
}

Tese de Doutorado

Orientador: Professor Titular Doutor Gustavo Ferraz de Campos Monaco

UNIVERSIDADE DE SÃO PAULO

FACULDADE DE DIREITO

São Paulo-SP

2020 

JOSÉ LUIZ SOUZA DE MORAES

\section{A ordem pública no direito internacional privado da família: parâmetros constitucionais}

Tese apresentada à Banca Examinadora do Programa de Pós-Graduação em Direito, da Faculdade de Direito da Universidade de São Paulo, como exigência parcial para obtenção do título de Doutor em Direito, na área de concentração Direito Internacional, sob a orientação do Professor Titular Doutor Gustavo Ferraz de Campos Monaco.

UNIVERSIDADE DE SÃO PAULO

FACULDADE DE DIREITO

São Paulo-SP

2020 
Catalogação da Publicação

Serviço de Biblioteca e Documentação

Faculdade de Direito da Universidade de São Paulo

Moraes, José Luiz Souza de

A ordem pública no direito internacional privado

da família: parâmetros constitucionais ; José Luiz

Souza de Moraes ; orientador Gustavo Ferraz de Campos Monaco -- São Paulo, 2020.

$297 \mathrm{p}$.

Tese (Doutorado - Programa de Pós-Graduação em Direito Internacional) - Faculdade de Direito, Universidade de São Paulo, 2020.

1. Direito internacional privado. 2. Ordem pública internacional. 3. Controle de

constitucionalidade da lei estrangeira. 4. Bloco de constitucionalidade. 5. Princípio do não retrocesso. I. Monaco, Gustavo Ferraz de Campos, orient. II. Título. 
BANCA EXAMINADORA 

À minha mãe-pai Evani e às minhas irmãs Anna e Paula, por todo o amor que sempre me deram.

À Renata, à Amanda, à Isabella e ao Luiz Augusto, pelo aprendizado diário do amor.

Ao теи pai, meu eterno amor e modelo, sempre a nos proteger e iluminar. 



\section{AGRADECIMENTOS}

Impossível não começar por quem tornou isto possível, pois tudo tenho a agradecer ao meu querido professor Gustavo Monaco, por ter acreditado em mim e no meu projeto acadêmico, na velha e sempre nova academia, um caminho que começamos há mais de sete anos. Nele tenho um amigo, orientador, modelo e um mestre a seguir os passos.

Aos amigos Wolf, Jean, Solano, Raquel, Kim, André, Janice e todos os outros que os bancos da sanfran me deram de presente. As melhores risadas, lições e projetos. Muito aprendi e sempre aprenderei com todos eles.

À memória de meu pai e avós, em especial ao meu avô Mario Arantes, que também se sentou nesses mesmos bancos e que continua a iluminar os meus passos por esses corredores, com o caráter e o bom orgulho sempre presentes.

Às minhas amadas mãe, irmãs e sobrinha por me apoiarem, sempre incondicionalmente, em todos os momentos da minha vida.

Aos meus filhos Amanda, Isabella e Luiz Augusto e à minha amada Renata que, parafraseando Florbela Espanca, já não são sequer a razão do meu viver, pois são já toda a minha vida. 



\section{RESUMO}

MORAES, José Luiz Souza de. A ordem pública no direito internacional privado da família: parâmetros constitucionais. 2020. 297 p. Tese (Doutorado em Direito) - Faculdade de Direito da Universidade de São Paulo, São Paulo, 2020.

A tese analisa a ordem pública internacional e a compatibilidade da lei estrangeira com os valores sociais do foro, consubstanciados de forma concentrada em sua Constituição. Aponta a necessidade da adoção de um paradigma constitucional mais restrito do que o utilizado para o controle de constitucionalidade das leis nacionais, a dos preceitos fundamentais constitucionais. Esses preceitos que parametrizam a ordem pública desbordam a Constituição formal e são encontrados no chamado bloco de constitucionalidade. Pesquisa os limites possíveis de aplicação da ordem pública, como a excepcionalidade e intervenção mínima, a vedação da surpresa, o mínimo dano à lei estrangeira e os efeitos atenuados na ordem pública de proximidade. Também apresenta a necessidade de que seja buscada a interpretação da lei estrangeira que melhor se coadune com a Constituição do foro sem que ocorra a sua indevida nacionalização. Indica a importância da evolutiva proteção da ordem pública aos direitos fundamentais, evitando retrocessos pela influência do fenômeno do political backlash. Por fim, aponta que a constitucionalização do direito de família tornou a exceção da ordem pública ancorada nos valores regentes das relações familiares previstos no bloco de constitucionalidade, com destaque à pluralidade de modelos familiares, aos princípios da dignidade, da afetividade, da igualdade, do melhor interesse das crianças e adolescentes e da proteção dos idosos e das pessoas com deficiência no âmbito familiar.

Palavras-chave: Direito internacional privado; Ordem pública internacional; Controle de constitucionalidade da lei estrangeira; Bloco de constitucionalidade; Princípio do não retrocesso; Preceitos fundamentais constitucionais; Political backlash; Proximidade; Afetividade; Direito de família; Homoafetividade; Melhor interesse da criança; Pessoa com deficiência. 


\begin{abstract}
MORAES, José Luiz Souza de. Public policy in international family law: constitutional parameters. 2020. 297 p. Thesis (Doctor in Law) - Faculdade de Direito da Universidade de São Paulo, São Paulo, 2020.

This thesis analyses international public policy and the suitability of the foreign law with the country's social values, which are embodied, in a concentrated way, in its Constitution. It indicates the need to adopt a narrower constitutional paradigm than the one used to control the constitutionality of national laws, the constitutional fundamental precepts. These precepts that parameterize public order override the formal constitution and are found in the so-called constitutionality block. It researches the possible limits of the application of public order, such as the exceptionality and minimum intervention, the prohibition of surprise, the minimum damage to foreign law and the attenuated effects on the public order of proximity. The thesis also points out the importance of the interpretation of the foreign law that best fits the constitution of the country, avoiding its improper nationalization. It highlights the importance of the evolving public policy protection to fundamental rights, so to avoid the setbacks related to the political backlash phenomenon. Finally, the study points out that the family law constitutionalizing process attached public policy exception to family relationship regent principles provided for in the constitutional block,, with special focus on family models plurality and the principles of, dignity, affectivity, equality, children and teenager's best interest and elderly and handicapped people protection within family context.
\end{abstract}

Keywords: Private international law; International public policy; Foreign law constitutional control; Constitutional block; Regressive prohibition principle; Constitutional fundamental precepts; Political backlash; Proximity; Affectivity; Family law; Homo-affectivity; Child best interest; Handicapped person. 


\section{RESUMÉ}

MORAES, José Luiz Souza de. L'ordre public dans le droit international privé de la famille: paramètres constitutionnels. 2020. 297 p. Thèse (Doctorat en Droit) - Faculdade de Direito da Universidade de São Paulo, São Paulo. 2020.

Cet étude se propose d'analyser l'ordre public international et la compatibilité du droit étranger avec les valeurs sociales insérées de manière concentrée dans la constitution du for. Elle met accent sur la nécessité d'adopter un contrôle de constitutionnalité plus étroit que celui appliqué aux lois nationales, lequel doit avoir pour base les préceptes constitutionnels fondamentaux. Ces préceptes qui paramètrent l'ordre public vont au-delà de la constitution formelle et se retrouvent dans le bloc de constitutionnalité. La recherche se penche sur les limites à l'application de l'ordre public, à l'instar de l'exception et l'intervention minimales, de l'interdiction de la surprise, de l'atteinte minimale au droit étranger et des effets atténués sur l'ordre public de proximité; elle fait valoir la nécessité d'une interprétation de la loi étrangère selon la constitution du for, sans pour autant procéder à sa "nationalisation". Elle incite une protection croissante de l'ordre public en matière de droits fondamentaux, afin d'éviter les revers liés à l'influence du phénomène appelé "political backlash". Enfin, la recherche tente de démontrer que la constitutionnalisation du droit de la famille a permis de rapprocher l'ordre public des valeurs propres aux relations familiales intégrées au bloc constitutionnel, et notamment la pluralité des modèles familiaux, les principes de dignité, d'affection et d'égalité, l'intérêt supérieur de l'enfant, ainsi que la protection des personnes âgées et handicapées.

Mots-clés: Droit international privé; Ordre public international; Contrôle de constitutionnalité; Droit étranger; Préceptes constitutionnels fondamentaux; Bloc de constitutionnalité; Principe de non-régression (effet cliquet); "Political backlash"; La proximité; L'affectivité; Droit de la famille; "Homoaffectivité"; L'intérêt supérieur de l'enfant; Personne handicapée. 



\section{SUMÁRIO}

INTRODUÇÃO

CAPÍTULO I - ORDEM PÚBLICA NO DIREITO INTERNACIONAL PRIVADO ...... 27

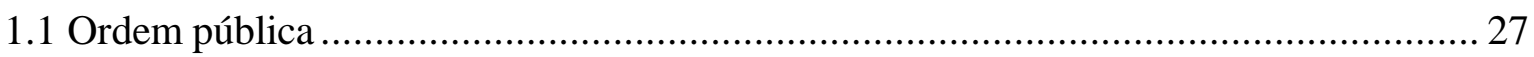

1.1.1 Polissemia e identidade: uma delimitação necessária .......................................... 32

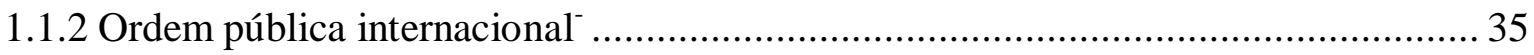

1.1.3 Problemas: subjetivismo, chauvinismo e insegurança jurídica .............................. 44

1.1.4 Normas de aplicação imediata, necessárias, imperativas ou lois de police:

uma necessária diferenciação .................................................................... 48

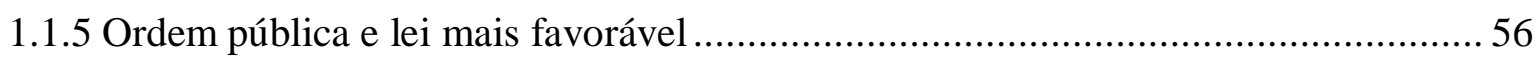

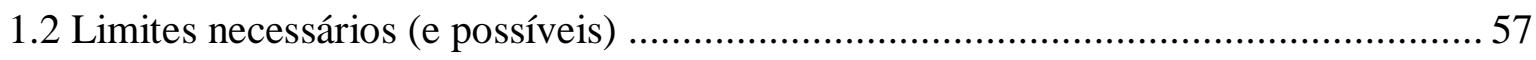

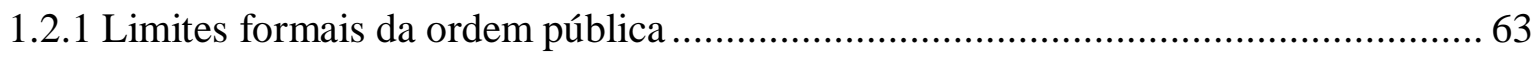

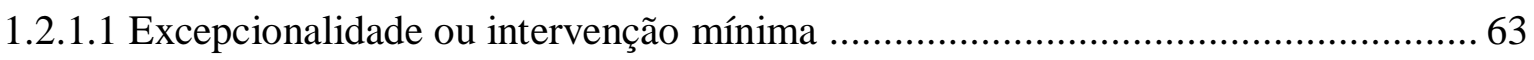

1.2.1.2 Dever de fundamentar e vedação da surpresa .............................................. 67

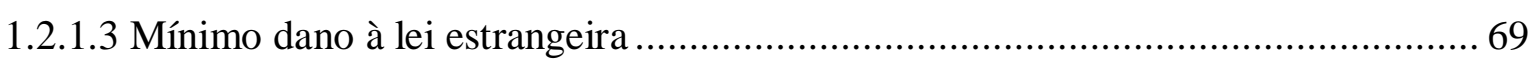

1.2.1.4 Efeitos atenuados: a ordem pública de proximidade ...................................... 74

1.2.1.5 Aplicação da ordem pública e criação de lacunas e antinomias............................ 79

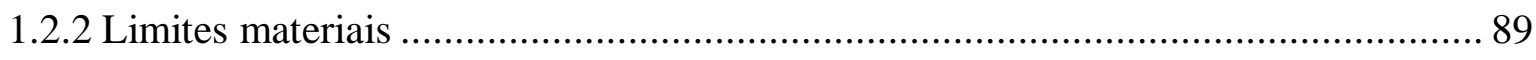

1.2.2.1 Constituição como parâmetro substancial da ordem pública ................................ 89

1.2.2.2 Lei estrangeira perante sua própria Constituição .............................................. 90

1.2.2.3 Constituição e regras conflituais do foro .......................................................... 93

1.2.2.4 Constituição do foro como fundamento de aplicação da lei estrangeira.

Ordem pública como locus de verificação de (in)compatibilidade ....................... 95

1.2.2.5 Recepção constitucional no tempo e seu paralelo nos conflitos de normas

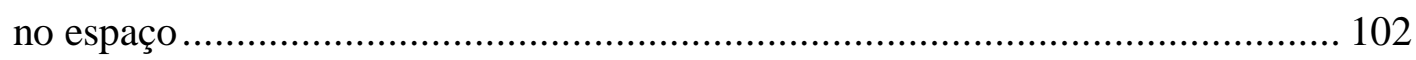

1.2.2.5.1 Irrelevância do parâmetro da constitucionalidade formal ............................... 106

1.2.2.5.2 Parâmetro valorativo para o controle das normas pré-constitucionais e estrangeiras perante a Constituição da República ......................................... 108

1.2.2.6 Preceito fundamental como parâmetro da ordem pública na norma constitucional brasileira

1.3 Ordem pública e o paradigma brasileiro de controle do bloco de constitucionalidade120 
1.3.1 Incompatibilidades sistêmicas ( $a d h o c)$. Necessidade da interpretação conforme a Constituição

1.3.2 Ordem pública e seus parâmetros infraconstitucionais

1.3.3 Ordem pública e convencionalidade. A incompatibilidade da lei estrangeira com os tratados internacionais internalizados

1.3.4 Tratados internalizados relativos ao direito de família

1.3.5 Direito penal como extensão do parâmetro constitucional de ferimento à ordem pública do foro

1.3.6 Outros parâmetros infraconstitucionais de ferimento à ordem pública do foro

1.3.7 Ordem pública no tempo e o princípio do não retrocesso. Um instrumento de controle à volatilidade da ordem pública

1.3.7.1 Origem histórica do instituto

1.3.7.2 Aplicação da regra do não retrocesso no direito nacional

1.3.7.3 Núcleo constitucional intangível como fundamento de aplicação do não retrocesso

\section{CAPÍTULO II - ORDEM PÚBLICA NAS RELAÇÕES FAMILIARES}

PLURILOCALIZADAS 163

2.1 Pluralidade de modelos familiares no tempo e no espaço .........................................170

2.2 Afetividade como fator identificador das relações familiares ..................................175

2.3 Princípio da dignidade humana e o seu desdobramento familiar .............................178

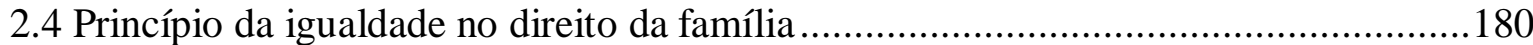

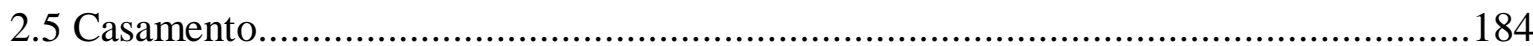

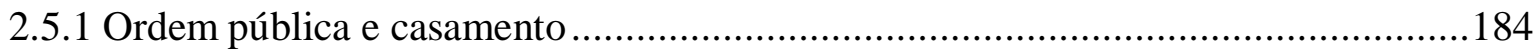

2.5.2 Casamento claudicante e o fundamento favor matrimonii ...................................186

2.5.3 Casamento infantil. Idade núbil e ordem pública internacional .............................189

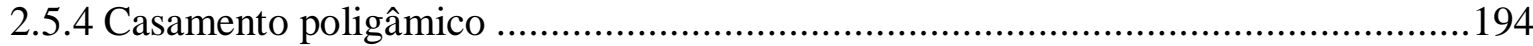

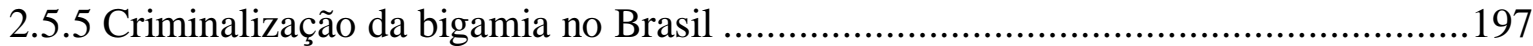

2.6 Poligamia e boa-fé, ordem pública e reconhecimento de efeitos do

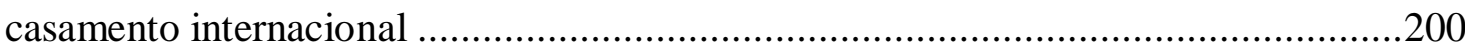

2.6.1 Ausência de boa-fé e fraude à lei ...................................................................207

2.6.2 Ordem pública e desforço comum. Vedação do enriquecimento sem causa como calibragem das questões patrimoniais.

2.7 Ordem pública aplicada ao casamento entre pessoas do mesmo sexo 
2.7.1 Capacidade, regra conflitual e sua especial relevância no casamento entre pessoas do mesmo sexo

2.7.2 Aplicação da ordem pública favor matrimonii e uniões entre pessoas do mesmo sexo

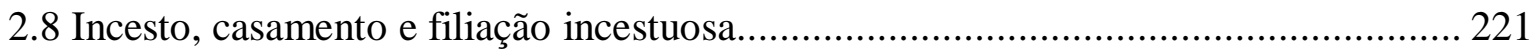

2.9 Ordem pública e as demais formas de união........................................................ 227

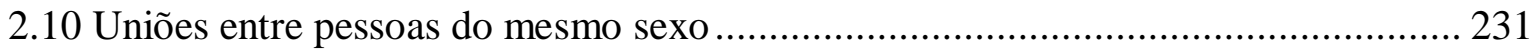

2.11 Ordem pública e uniões estáveis simultâneas ....................................................... 233

2.12 Ordem pública relativa ao divórcio, extinção de uniões e reconstituição familiar ... 235

2.12.1 Talaq - o repúdio muçulmano. Guet - o divórcio judaico ................................. 238

2.13 Ordem pública, filiação e proteção da criança, do adolescente e do jovem ............. 243

2.13.1 Princípio do melhor interesse da criança e do adolescente .................................. 245

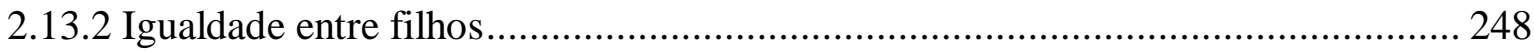

2.13.3 Ordem pública no sequestro internacional de crianças........................................ 249

2.13.4 Adoção. Lei imperativa ou ordem pública? ...................................................... 253

2.13.5 Reprodução assistida, gestação por outrem e ordem pública.............................. 259

2.13.6 Paternidade socioafetiva, adoção à brasileira e ordem pública ............................ 265

2.14 Ordem pública e capacidade da pessoa com deficiência. Convenção de

Nova Iorque como parâmetro de calibragem em nível constitucional ..................... 268

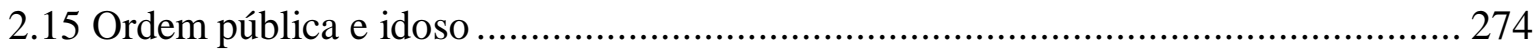

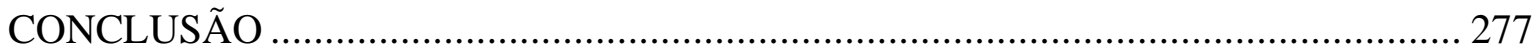

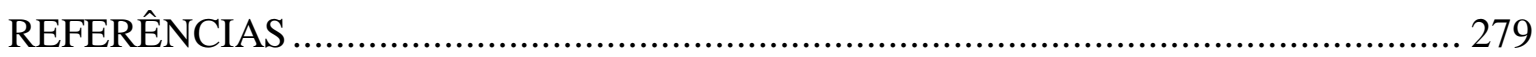





\section{INTRODUÇÃO}

As diversas transformações sociais havidas na segunda metade do século passado e a crescente internacionalização das relações jurídicas surgidas do complexo fenômeno da "globalização" 1 ainda causam acelerado crescimento das relações sociais, culturais, econômicas e jurídicas no campo transnacional.

A pluralidade das relações jurídicas transnacionais é sensível à aceleração causada pela popularização dos meios de transporte, pela migração massiva de grupos de pessoas em razão de conflitos, crises econômicas e questões ambientais, bem como a mundialização dos meios de comunicação e o afrouxamento de fronteiras geopolíticas, que apesar das resistências de alguns Estados, estão cada vez mais invisíveis e transponíveis. ${ }^{2-3}$

Esse panorama mundial pós-moderno multiplicou as relações humanas envolvendo os ordenamentos jurídicos de diversos Estados e desafia o direito internacional privado

\footnotetext{
${ }^{1} \mathrm{O}$ fenômeno da globalização é complexo e possui diversos aspectos; referindo-se exclusivamente à sua influência na transformação social, "recent theorists conceive of globalization as linked to the growth of social interconnectedness across existing geographical and political boundaries. In this view, deterritorialization is a crucial facet of globalization. Yet an exclusive focus on it would be misleading. Since the vast majority of human activities is still tied to a concrete geographical location, the more decisive facet of globalization concerns the manner in which distant events and forces impact on local and regional endeavors" (TOMLINSON, John. Globalization and culture. Cambridge: Polity Press, 1999 apud SCHEUERMAN, William. Globalization. In: ZALTA, Edward N. (ed.). The Stanford Encyclopedia of Philosophy. Winter 2018 Edition. Disponível em: https://plato.stanford.edu/archives/win2018/entries/globalization/. Acesso em: 02 nov. 2019), não nos descurando de que o fenômeno apresenta outros aspectos, em especial na economia, o ramo de conhecimento que é a sua origem conceitual.

2 "La culture postmoderne est caractérisée essentiellement par quatre phénomènes: le pluralisme, la communication, la narration et le retour des sentiments. Ces traits typiques postmodernes sont en train d'influencer le développement du droit y compris les solutions de conflits de lois et de juridictions." (JAYME, Erik. Identité culturelle et intégration: le droit international privé postmoderne. Recueil des Cours, Académie de Droit International de La Haye, v. 251, p. 36, 1995).

3 "C'est la mobilité accrue des êtres humains facilitée par l'extraordinaire développement des transports et due à des causes aussi diverses que le tourisme, l'accroissement des contrats de travail internationaux, les mouvements de population liés aux difficultés économiques ou politiques. La rapidité des transports doit être soulignée car elle ne peut laisser indifférent l'internationaliste: la distance dans l'espace doit nécessairement être appréciée en fonction du temps nécessaire pour la franchir. Comme l'a fort justement écrit F. Rigaux, 'L'espace ne se laisse pas dissocier du temps', et l'on verra les conséquences à en tirer pour le jeu de l'ordre public international." (GAUDEMET-TALLON, Hélène. La désunion du couple en droit international privé. Recueil des Cours, Académie de Droit International de La Haye, v. 226, p. 25, 1991).
} 
(DIPr) a solucionar os incontáveis conflitos de normas, caracterizados pela pluralidade de ordens jurídicas $^{4}$ envolvidas, em uma crescente complexidade. ${ }^{5}$

A chamada "globalização" gera, por outro lado, resistência e reação. Em uma mesma região geográfica, e mesmo entre Estados vizinhos, a busca de alguns povos de movimentos contrários a uma "mundialização de valores" busca a imposição, por vezes normativa, de suas características culturais, valorativas e históricas, em uma tentativa de manter a sua identidade e história, em resistência a um mundo "standarizado". O respeito a esse multiculturalismo em um mundo globalizado é com o que o DIPr deve lidar. ${ }^{6}$

É diante desse quadro de crescente e complexa internacionalização das relações humanas que devem ser utilizados os instrumentos tradicionalmente previstos nos métodos

\footnotetext{
${ }^{4}$ Overbeck aponta a unificação do direito internacional privado dos Estados como uma das soluções para gerar a harmonia de decisões e, de forma poética, compara esse esforço à construção de um túnel a ligar dois países, devendo cada qual atacar o seu lado da montanha, não sendo suficiente apenas a boa vontade, mas uma coordenação de trabalhos com técnica e uma finalidade comum: "Quel que soit leur mérite, les tentatives de parvenir à l'harmonie des solutions au moyen d'un droit international privé qui reste le droit de chaque Etat semblent quelque peu hasar entreprise nous suggère une comparaison avec la construction du tunnel routier du Saint-Bernard qui relier notre pays à l'Italie. De chaque côté du col, une société nationale poursuit l'attaque de la montagne. Mais est-ce que les sociétés italienne suisse dans l'espoir de rencontrer quelque part les mineurs avançant de l'autre côté? Il saute aux yeux que non, et que le tracé du été minutieusement calculé d'un commun accord, qu'on s'est entendu sur les dimensions du tunnel, son inclinaison, toute son exécution. Et bien, la coordination des systèmes par les seuls moyens du droit national nous paraît beaucoup ressembler à une construction de tunnel sans plan d'ensemble. Avances de chaque côté risquent d'aboutir à deux tunnels séparés ou tout au moins à la bonne volonté à elle seule ne suffit pas." (OVERBECK, Alfred Eugène von. Divers aspects de l'unification du droit international privé spécialement en matière de successions. Recueil des Cours, Académie de Droit International de La Haye, v. 104, p. 529-631, 1961).

${ }^{5}$ Como bem aponta Ferrer Correia: "Como há cento e cinquenta anos, e apesar de muito que se avançou, sobretudo no interior de certos espaços geográficos, a caminho de uma unificação do direito, continuam a existir divergências inúmeras e muitas vezes profundas entre as várias legislações nacionais." (CORREIA, António Ferrer. Lições de direito internacional privado I. 9. reimp. da edição de outubro de 2000. Coimbra: Almedina, 2018. p. 406).

${ }^{6}$ Apesar da complexidade da matéria, o fato é que sua finalidade, como bem aponta Michael Bogdan, é deveras singela: encontrar soluções razoáveis para os problemas cotidianos das relações jurídicas familiares ou comerciais envolvendo um elemento de estraneidade (BOGDAN, Michael. Private international law as component of the law of the forum: general course. Recueil des Cours, Académie de Droit International de la Haye, v. 348, p. 28, 2011).
} 
conflituais do $\operatorname{DIPr}^{7}$. Caberá ao aplicador satisfazer de forma integral a proteção dos seres humanos, em especial nas relações familiares, a principal faceta do indivíduo. ${ }^{8}$

Para a proteção dessas relações humanas pelo DIPr, os seus instrumentos se mostram suficientes ou seriam necessários outros $?^{9-10}$

As mudanças do paradigma jurídico no mundo do direito, a partir do final do século passado, mostram a necessária coadunação do sistema clássico, baseado em um método conflitual tradicional com fulcro nas regras de conexão constituídas de arquétipos rígidos e indiretos, que indicam a aplicação da lei de determinado Estado por meio de modelo binário de aplicação do direito exclusivamente na incidência ou não de uma regra positivada, aparentemente indiferente, com o ideal de realização de justiça, em razão de ser um direito formal, sem conteúdo.

\footnotetext{
${ }^{7}$ Sobre a denominada crise do DIPr, conferir: AUDIT, Bernard. Le caractère fonctionnel de la règle de conflit: sur la crise des conflits de lois. Recueil des Cours, Académie de Droit International de la Haye, v. 186, p. 231, 1984.

8 "La aparición de cuestiones nuevas que interesan al Derecho internacional privado se debe principalmente a dos fenómenos distintos y en cierto modo contradictorios. Por un lado, a un aumento desarrollo continuado de las relaciones internacionales a partir la Segunda Guerra Mundial principalmente. Por el otro, a una creciente importancia del papel del Estado en la regulación de las relaciones privadas no sólo en las de carácter económico, sino también en las de carácter familiar." (BOUZA VIDAL, Nuria. Problemas de adaptación en derecho internacional privado e interregional. Madrid: Editorial Tecnos, 1977. p. 12).

${ }^{9}$ Como indica Bucher, a respeito do imenso pluralismo da concepção familiar em razão das diferentes culturas: "Ce pluralisme des structures familiales est cependant étroitement lié à la situation sociale et politique des Etats occidentaux ou industrialisés, qui connaissent un droit laïcisé et le plus souvent unifié. Cette conception de la famille apparaît fort éloignée, plus que par le passé, de celle des Etats multicommunautaires, dans lesquels les coutumes ou la religion marquent encore profondément le statut personnel et familial de chacun des différents groupes de la population. Alors que dans les Etats occidentaux l'individualisation s'est développée au point de faire éclater l'unité familiale, de très nombreux autres Etats restent attachés à la valeur traditionnelle de l'identité familiale fondée sur le mariage et déterminée par la personne du mari et père." (BUCHER, Andreas. La famille en droit international privé. Recueil des Cours, Académie de Droit International de La Haye, v. 283, p. 21, 2000).

${ }^{10}$ Como bem aponta Nadia de Araujo: "A proteção da pessoa humana é hoje o objetivo precípuo de todo o ordenamento jurídico, e ultrapassou as fronteiras iniciais do direito público, integrando os princípios norteadores do direito constitucional, e influenciando também a sistemática do DIPr. Assume cada dia mais relevância a interpretação e a utilização dadas à questão da proteção da pessoa humana e de sua dignidade, em todas as áreas do direito, em especial no direito privado." (ARAUJO, Nadia de. Direito internacional privado: teoria e prática brasileira. 5. ed. atual. e ampl. Rio de Janeiro: Renovar, 2011. p. 14).
} 
Esse modelo de neutralidade axiológica, um DIPr puro e indiferente aos resultados jurídicos obtidos ${ }^{11}$, pode fazer frente à mudança paradigmática ocorrida nas últimas décadas de direito como realização de justiça?

Nós cremos que sim, e encontramos na exceção da ordem pública o principal instrumento para aplicação do DIPr na busca de uma "justiça mais efetiva"12, sem a necessidade de invenção de "novos instrumentais" para a satisfação dos interesses perseguidos pelo direito dos "novos tempos". ${ }^{13}$ Se no DIPr as regras de conflito são neutras, no campo da ordem pública, a neutralidade dá espaço à busca da harmonização sistêmica (ad hoc) e da justiça para o caso concreto.

No Brasil, a aplicação do DIPr ocorre por meio dos conceitos-quadro previstos nos $\operatorname{artigos} 7^{\circ}$ a 11 da Lei de Introdução às Normas do Direito Brasileiro (LINDB) ${ }^{14}$ e por tratados internacionais internalizados no nosso ordenamento. Essa escassa normatização é com o que o intérprete se depara para realizar o enquadramento das situações de vida postas em análise pelo foro, de acordo com os critérios escolhidos pelo legislador, mesmo

\footnotetext{
${ }^{11}$ RAMOS, Rui Manuel Gens de Moura. Direito internacional privado e Constituição: introdução a uma análise das suas relações. 3. reimpr. Coimbra: Coimbra Editora, 1994. p. 96 et seq.

${ }^{12}$ Há outros instrumentos no DIPr para buscar essa finalidade, em especial a adoção de normas de conexão múltiplas que, no entanto, são raras, diante da diminuta e antiga normatização do DIPr no Brasil. A utilização de conexões alternativas ou cumulativas permite de forma objetiva que o intérprete busque a satisfação da proteção do bem jurídico principal apontado pelo legislador, afastando-o da aplicação binária. Contudo, mesmo nessas hipóteses, como ocorre na previsão do artigo $5^{\circ}$, XXXI, da Constituição Federal (CF), com similar redação no artigo 10 , parágrafo $1^{\circ}$, que possibilita ao aplicador do direito a escolha da lei mais favorável ao cônjuge e aos filhos brasileiros, não está imune a críticas e a grandes dificuldades na sua aplicação. Por todos, ver: REIS, Gabriel Valente dos. Por uma análise cosmopolita da determinação da lei aplicável. 2012. 128 p. Dissertação (Mestrado) - Faculdade de Direito da Universidade de São Paulo, São Paulo, 2012. Disponível em: https://www.teses.usp.br/teses/disponiveis/2/2135/tde-22042013114640/publico/Gabriel_Valente_dos_Reis.pdf. Acesso em: 10 dez. 2019.

${ }^{13}$ AZEVEDO, Antonio Junqueira de. O direito pós-moderno e a codificação. Revista da Faculdade de Direito, Universidade de São Paulo, São Paulo, v. 94, p. 3-12, jan. 1999. Disponível em: http://www.revistas.usp.br/rfdusp/article/view/67429/70039. Acesso em: 19. jun. 2018.

14 “Continuar com o sistema do DIPr do século XIX, que não se preocupa com os resultados obtidos quando é preciso usar a regra de conexão, é correr o risco de ignorar os anseios da sociedade, dando-lhe as costas. Utiliza-se uma técnica sofisticada - o método conflitual -, mas cega às necessidades do indivíduo." (ARAUJO, Nadia de, Direito internacional privado: teoria e prática brasileira, cit., p. 15).
} 
após a passagem de quase oitenta anos de sua previsão. ${ }^{15}$ aplicação acarreta a incidência de valores ${ }^{16}$ e realidades que, não raro, conflitam com os valores eleitos pelos legisladores ${ }^{17}$, em especial os constitucionais ${ }^{18}$, que àqueles sucederam no

\section{Essa tempo.}

15 Aponta Gaudemet-Tallon que a neutralidade das regras de conexão impede o nacionalismo, gera a vantagem da inexigência de que se conheça o direito material dos Estados envolvidos e permite a localização objetiva dos conflitos (GAUDEMET-TALLON, Hélène. Le pluralisme en droit international privé: richesses et faiblesses (le funambule et l'arc-en-ciel): cours général. Recueil des Cours, Académie de Droit International de La Haye, v. 312, p. 187, 2005). Por outro lado, Mohamed Salah aponta a necessidade de não haver uma cegueira do DIPr em relação às consequências do direito substancial, em especial no que tange à proteção de partes fracas na relação jurídica:“C'est aussi pousser à l'extrême l'idée selon laquelle la fonction du droit international privé est exclusivement une fonction de répartition et de classement indifférente au contenu des règles du droit substantiel. Aussi, la plupart des systèmes juridiques qui ont organisé, en droit matériel, une protection de la partie faible ont souvent été amenés à prévoir des règles de conflit tenant compte de la finalité protectrice du droit substantiel. Incorporant des considérations de justice matérielle, de telles règles s'éloignent de l'image d'une méthode conflictualiste fonctionnant de manière neutre et quasi mécanique." (MOHAMED SALAH, Mohamed Mahmoud. Loi d'autonomie et méthodes de protection de la partie faible en droit international privé. Recueil des Cours, Académie de Droit International de La Haye, v. 315, p. 164-165, 2005).

${ }^{16}$ Nesse sentido: "O que ora está em causa é, no fundamental, toda uma corrente de pensamento para quem o DIP não é já um exótico sector do jurídico dominado obcessivamente por preocupações de garantia da previsibilidade da lei que regerá as relações internacionais - escopo este identificado com o interesse primacial das partes nelas interessadas - mas antes um ramo do direito que como os demais, ainda que por formas e intensidade diversas, participa igualmente duma tarefa de modelação da sociedade a que se dirige e que, por isso mesmo, à sua maneira embora, comunga da mesma Weltangschauung que subjaz a todo o Direito e tenta realizar, no seu campo próprio, aqueles fins a que o ordenamento no seu todo vai colimado. Mais simplesmente, o DIP passa a ser responsabilizado - e agora não apenas por via de excepção como sucedia a ordem pública internacional - pela promoção dos valores que a comunidade sente como seus, para tanto os plasmando nos critérios em ordem aos quais são dirimidos os conflitos de interesses entre os particulares e entre esses e o Estado. Dele se devendo pois dizer, como o fez Kronstein, referindo-se ao Direito em geral, que 'o DIP não é neutro, é antes inseparável da Ordem, na verdade da nossa ordem, daquela em que a nossa lei acredita'.” (RAMOS, Rui Manuel Gens de Moura, Direito internacional privado e Constituição: introdução a uma análise das suas relações, cit., p. 101-102).

17 "Perante o exposto parece estarmos bastante longe do direito de aplicação do direito, valorativamente neutro e fundado nos interesses das partes, que era o DIP de Savigny. O longo caminho percorrido no sentido da politicização do DIP leva-nos a pensar se não se inverteu de vez o complexo de inferioridade dos publicistas em face do direito civil, de que fala Rogério Soares. Importa no entanto ver em que medida se justificam e colhem aplauso as propostas da escola política. Um ponto pode desde já considerar-se assente, a complexificação crescente da sociedade e a invasão dos interesses colectivos em problemas que até agora relevavam do mero direito privado conduziram à demarcação, se bem que insegura e sobretudo oscilante, de uma zona que, não sendo ainda do domínio do direito público, não pertence já ao direito privado clássico.” (RAMOS, Rui Manuel Gens de Moura, Direito internacional privado e Constituição: introdução a uma análise das suas relações, cit., p. 146).

18 “A consagração da dignidade da pessoa humana como valor central do ordenamento jurídico e como um dos fundamentos da República brasileira (art. $1^{\circ}$, III, CF) foi o vetor e o ponto de virada para essa gradativa ressignificação da família. A Carta de 1988 inspirou a repersonalização do Direito Civil, fazendo com que as normas civilistas passassem a ser lidas a partir da premissa de que a pessoa humana é o centro das preocupações do Direito, que é dotada de dignidade e que constitui um fim em si próprio. A família passou, então, a ser compreendida juridicamente de forma funcionalizada, ou seja, como um instrumento (provavelmente o principal) para o desenvolvimento dos indivíduos e para a realização de seus projetos existenciais. Não é mais o indivíduo que deve servir à família, mas a família que deve servir ao indivíduo." (STF - RE n. 878.694/MG, voto rel. Min. Roberto Barroso, p. 7). 
Nesse diapasão, a exceção da ordem pública tem importante papel e atua como verdadeiro filtro para o afastamento de soluções da aplicação do método conflitual que venham a ser incompatíveis com valores sociais do foro. Contudo, esse princípio não está imune a críticas, pois devido à - aparentemente - ampla discricionariedade que envolve a sua aplicação, pode sujeitar o direito a subjetivismos e à insegurança jurídica.

Sem dúvida, a ordem pública revestida de puro subjetivismo e abstração exagerada fere gravemente a segurança jurídica. Por outro lado, a sua racionalização e utilização escorreita diante do método conflitual e com as balizas do direito interno do foro, impede a aplicação meramente potestativa do direito, bem como e ao mesmo tempo afasta a aplicação automatizada das regras materiais positivadas no estrangeiro, decorrendo daí a sua função protetiva do ordenamento jurídico e de toda a ordem social.

Esse princípio norteador comprova que há à disposição do aplicador do direito um conjunto de ferramentas clássicas de DIPr, que deve ser utilizado com o objetivo de afastar a aplicação meramente binária do DIPr, já que as regras, como as constantes da LINDB, de forma isolada não admitem eficácia gradativa e somente podem ser ou não válidas em um sistema que não permite matizes de eficácia, aplicabilidade e justiça.

Contudo, a ordem pública não pode ser instrumento de provincianismo com a chauvinista sobreposição do direito do foro, mais fácil, pois de amplo conhecimento do aplicador, mas deve ser forma de racionalizar a aplicação de valores individuais e sociais preestabelecidos na ordem jurídica, em especial no que tange à proteção do direito de família, com a rechaça a estatutos odiosos ${ }^{19}$ aos valores protegidos em nosso ordenamento. $^{20}$

Portanto, veremos que a ordem pública tem papel principal nesse instrumental clássico do DIPr, tornando-o suficiente para a busca da justiça mais efetiva, afastando a disciplina de sua não raramente criticada neutralidade, sem a necessidade de que sejam criados novos mecanismos, ou erroneamente adaptados mecanismos não afetos ao DIPr, descaracterizando-o e até apequenando o seu conteúdo e função.

\footnotetext{
${ }^{19}$ Em referência à escola estatutária de Bartolo como ideia precursora de ordem pública, mas com ela não se confundindo.

${ }^{20}$ MOHAMED SALAH, Mohamed Mahmoud, Loi d'autonomie et méthodes de protection de la partie faible en droit international privé, cit., p. 141-264.
} 
Por outro lado, é necessário deixar claro que esta pesquisa nem sequer ousa apontar uma definição perfeita do que seja a ordem pública e seus estritos limites, pois nenhum autor, legislação ou jurisprudência foram capazes de elaborar uma definição perfeita das matérias contrárias a esse princípio, seja em razão de ser ele fluido e variar de ordenamento para ordenamento, seja pela sua constante mutação temporal, mesmo diante da mesma sociedade, sendo, nas palavras de Erick Jayme ${ }^{21}$, o tema mais angustiante do DIPr.

E por que a ordem pública do direito internacional da família?

A intensa mobilidade transfronteiriça, com a intensificação migratória crescente desde o final da Segunda Guerra Mundial, tornou cada vez mais comuns relações familiares compostas de pessoas de distintas nacionalidades, de diversos domicílios e residências, com a ocorrência dos chamados conflitos móveis, em que são potencialmente formados vínculos com diversos ordenamentos jurídicos, considerados sucessivamente relavantes para a regência de direitos e deveres dos membros da família.

O papel protetivo da ordem pública é desempenhado com ainda mais importância quando destinado à proteção da família, afinal é esse o principal núcleo de interação do indivíduo com a sua sociedade e, em razão disso, entendemos que ele apresenta peculiaridades em relação às suas demais funções, sendo possível afirmar a existência de uma ordem pública internacional especial do direito de família, que a distancia de sua aplicação geral.

Reconhecemos ainda que essa proteção conta com parâmetros que devem conduzir o aplicador da ordem pública sempre conforme a Constituição, buscando ativamente meios de tornar a aplicação do DIPr harmônica com os preceitos máximos do ordenamento jurídico. É sobre essa especialidade e os contornos que a marcam que trataremos nesta pesquisa.

Por fim, é necessário apontar o ponto referencial adotado pela presente pesquisa, o ordenamento jurídico brasileiro, em especial no que tange ao direito constitucional pátrio e suas características peculiares.

${ }^{21}$ JAYME, Erik. Métodos para la concretización del orden público en el derecho internacional privado. Revista de la Facultad de Ciencias Jurídicas y Políticas, Caracas, Universidad Central de Venezuela, n. 82, p. 218-219, 1991. 


\section{CONCLUSÃO}

A principal conclusão a que se chega na análise da ordem pública é que os valores sociais nela contidos possuem forte ancoragem na ordem constitucional, pois na aplicação da lei estrangeira, a ordem pública será o locus de controle sui generis da compatibilidade dessa com preceitos fundamentais constitucionais.

Esse controle na ordem pública se afasta das características típicas do controle "comum" das normas nacionais, possuindo vínculos e características muito mais fortes com outra forma de controle de compatibilidade constitucional, o utilizado para a aferição da harmonia das normas pré-constitucionais com uma nova Constituição, a chamada recepção constitucional.

Assim, ao falarmos em compatibilidade constitucional da lei estrangeira, devemos ter em mente que estamos diante de uma natureza de controle de constitucionalidade sui generis, pois não se reconhece a lei estrangeira como inconstitucional no sentido comum de declaração da sua nulidade, como ocorre em regra com as demais normas jurídicas.

A lei estrangeira não vige erga omnes, mas sim inter partes em um caso concreto, em decorrência da aplicação das regras de conflito, tratando-se de um juízo sobre a aplicação ou não do direito estrangeiro, quando seja ele incompatível com o direito constitucional brasileiro de forma insuperável, sendo tal operação realizada na análise da incidência da exceção da ordem pública.

A compatibilidade da lei estrangeira com os valores do foro está consubstanciada de forma concentrada na sua Constituição, tendo como paradigma, no Brasil, os preceitos fundamentais constitucionais para verificação de relevantes lesões da norma estrangeira ao ordenamento constitucional, a legitimar a aplicação da ordem pública.

Concluímos, portanto, que não é na CF que a lei estrangeira encontra parâmetro para verificação de compatibilidade para fins da ordem pública, mas sim nos preceitos fundamentais constitucionais, pois assim como as normas pré-constitucionais não encontram parâmetro de controle na Constituição como um todo, apenas podendo ter sua 
validade verificada pela recepção, diante de sua compatibilidade e se não descumprirem preceitos fundamentais constitucionais, somente com a adoção do mesmo paradigma é que poderemos ter segurança e razoabilidade na verificação de quais são os valores a serem protegidos pela ordem pública brasileira.

Além disso, constatamos também que os preceitos fundamentais podem ser encontrados não somente no texto formal da Constituição, mas também fora dele, pois devemos reconhecer a existência desses preceitos no chamado bloco de constitucionalidade.

Ademais, vimos que quando mais de uma interpretação da lei estrangeira for admissível, deve ser buscada aquela que a torne compatível harmonicamente com a Constituição do foro, evitando-se ao máximo a que gere resultados absurdos ou intoleráveis aos valores desse ordenamento, apontando o intérprete a incompatibilidade constitucional de determinadas leituras alternativas que levariam à sua intolerância no foro, afastando-as e, ao mesmo tempo, buscando a interpretação que melhor preserve a sua origem, sem desnaturalizar a lei estrangeira, fazendo perder a sua essência.

A ordem pública também encontra uma outra barreira de ordem constitucional, a sua aplicação evolutiva, isto é, não permitindo que a mudança de valores sociais de forma momentânea venha a restringir de forma involutiva a proteção de direitos fundamentais já conquistada pela sociedade, por meio da vedação do retrocesso à proteção desses direitos. Em especial, as evoluções protetivas dos direitos fundamentais, de forma mais acentuada no que tange ao respeito à igualdade, sofrem hoje forte oposição política, denominada por Michael Klarman de political backlash.

Por fim, a constitucionalização do direito civil, em especial o direito de família, tornou a exceção da ordem pública ancorada nos valores regentes das relações familiares previstos na Constituição, com destaque à pluralidade de modelos familiares, aos princípios da dignidade, da afetividade, da igualdade, do melhor interesse das crianças e adolescentes e da proteção dos idosos e das pessoas com deficiência no âmbito familiar. 


\section{REFERÊNCIAS}

ACCIOLY, Hildebrando; SILVA, Geraldo Eulálio do Nascimento; CASELLA, Paulo Borba. Manual de direito internacional público. 24. ed. São Paulo: Saraivajur, 2019.

AGBODJAN, Serge. Controverse autour de la Lépi: une élection contraire aux principes des droits de l'homme. La Nouvelle Tribune, 02 Mar. 2011. Disponível em: http://www.lanouvelletribune.info/index.php/reflexions/opinion/7459-controverse-autourde-la-lepi-une-election-contraire-aux-principes-des-droits-de-lhomme. Acesso em: 12 jun. 2019).

ALMEIDA, Bruno Rodrigues de. O reconhecimento dos casamentos e parcerias entre pessoas do mesmo sexo no direito transnacional: pluralismo, dignidade e cosmopolitismo nas famílias contemporâneas. Tese (Doutorado) - Faculdade de Direito da Universidade do Estado do Rio de Janeiro, Rio de Janeiro, 2012.

ALVES, Felipe Delenogare; LEAL, Mônia Clarissa Henning. Judicialização e ativismo judicial: o Supremo Tribunal Federal entre a interpretação e a intervenção na esfera de atuação dos demais poderes. Rio de Janeiro: Lumen Juris, 2015.

ALVES, José Carlos Moreira. Direito romano. 14. ed. rev., corrigida e aum. Rio de Janeiro: Forense, 2008.

AMARAL JÚNIOR, José Levi Mello do. Controle de constitucionalidade evolução brasileira determinada pela falta do stare decisis. Revista dos Tribunais, São Paulo, v. 101, n. 920, p. 133-149, jun. 2012.

AMRAM, Denise. Pursuing the best interest of children in non-traditional families: a comparative overview. European Journal of Law Reform, v. 17, n. 2, p. 247-256, 2015.

APPIO, Eduardo Fernando. Direito das minorias. São Paulo: Revista dos Tribunais, 2009.

APPIO, Eduardo Fernando. Interpretação conforme a Constituição: instrumentos de tutela jurisdicional dos direitos fundamentais: de acordo com a Lei 9.868/99. Curitiba: Juruá, 2002.

ARAUJO, Nadia de. Direito internacional privado: teoria e prática brasileira. 5. ed. atual. e ampl. Rio de Janeiro: Renovar, 2011.

ARAUJO, Nadia de. Direito internacional privado e direitos fundamentais: uma perspectiva retórico-argumentativa do princípio da ordem pública. In: BRANT, Leonardo Nemer Caldeira (org.). Brasil e os novos desafios do direito internacional. Rio de Janeiro: Forense, 2004. p. 569-608.

AUDIT, Bernard. Le caractère fonctionnel de la règle de conflit: sur la crise des conflits de lois. Recueil des Cours, Académie de Droit International de la Haye, v. 186, p. 219-397, 1984. 
AUDIT, Bernard. Le droit international privé en quête d'universalité. Recueil des Cours, Académie de Droit International de la Haye, v. 305, p. 9-488, 2003.

ÁVILA, Humberto. Teoria dos princípios: da definição à aplicação dos princípios jurídicos. 12. ed. São Paulo: Malheiros. 2010.

AZEVEDO, Álvaro Villaça. Estatuto da família de fato: de acordo com o atual Código Civil, Lei no 10.406, de 10-01-2002. 3. ed. São Paulo: Atlas, 2011.

AZEVEDO, Antonio Junqueira de. O direito pós-moderno e a codificação. Revista da Faculdade de Direito, Universidade de São Paulo, São Paulo, v. 94, p. 3-12, jan. 1999. Disponível em: http://www.revistas.usp.br/rfdusp/article/view/67429/70039. Acesso em: 19 jun. 2018.

BAPTISTA, Luiz Olavo. Aplicação do direito estrangeiro pelo juiz nacional. Revista de Informação Legislativa, Brasília, v. 36, n. 142, p. 267-278, abr.jun. 1999. Disponível em: https://www2.senado.leg.br/bdsf/bitstream/handle/id/490/r142-21.PDF?sequence=4.

Acesso em: 10 jun. 2019.

BARROSO, Luís Roberto. O controle de constitucionalidade no direito brasileiro: exposição sistemática da doutrina e análise crítica da jurisprudência. 7. ed., rev. e atual. São Paulo: Saraiva, 2016.

BARROSO, Luís Roberto. Curso de direito constitucional contemporâneo: os conceitos fundamentais e a construção do novo modelo. 7. ed. São Paulo: Saraiva, 2018.

BARROSO, Luís Roberto. O direito constitucional e a efetividade de suas normas. 9. ed. Rio de Janeiro: Renovar, 2009.

BARROSO, Luís Roberto; BARCELLOS, Ana Paula de. O começo da história: a nova interpretação constitucional e o papel dos princípios no direito brasileiro. In: SILVA, Virgílio Afonso da (org.). Interpretação constitucional. São Paulo: Malheiros, 2007. p. 271-376.

BARTIN, Etienne. Une conception nouvelle de l'empire de la loi locale par opposition a la loi personnelle et a la loi territoriale. Recueil des Cours, Académie de Droit International de La Haye, v. 52, p. 583-642, 1935.

BATALHA, Wilson de Souza Campos. Tratado elementar de direito internacional privado: parte especial: comentários aos arts. 7 a 19 da Lei de Introdução ao Código Civil. São Paulo: Revista dos Tribunais, 1961. v. 2.

BATIFFOL, Henri. Aspects philosophiques du droit international privé. Revue Internationale de Droit Comparé, v. 10, n. 1, p. 190-194, janv./mars 1958. Disponível em: https://www.persee.fr/doc/ridc_0035-3337_1958_num_10_1_11788. Acesso em: 06 mar. 2019.

BATIFFOL, Henri. Principes de droit international privé. Recueil des Cours, Académie de Droit International de la Haye, v. 97, p. 431-574, 1959. 
BEVILÁQUA, Clóvis. Princípios elementares de direito internacional privado. 4. ed. Rio de Janeiro: Freitas Bastos, 1944.

BIHANNIC, Kévin. Repenser l'ordre public de proximité: d'une conception hiérarchique à une conception proportionnelle. Thèse (Doctorat en droit) - École Doctorale de Droit, Universite Paris I - Pantheon-Sorbonne, Paris, 2017. Disponível em: https://tel.archivesouvertes.fr/tel-01778232/document. Acesso em: 13 set. 2019.

BITENCOURT, Cezar Roberto, Tratado de direito penal: parte geral. 25. ed. São Paulo: Saraiva, 2019.

BITTENCOURT, Edgard de Moura. Concubinato: família natural, direitos da concubina, investigação de paternidade, guarda de filhos, acidentes do trabalho e previdência, outros efeitos da união livre. São Paulo: Leud, 1975.

BOBBIO, Norberto. A era dos direitos. Tradução: Carlos Nelson Coutinho. Nova ed., 7. tiragem. Rio de Janeiro: Elsevier, 2004.

BOBBIO, Norberto. Teoria geral do direito. Tradução: Denise Agostinetti; revisão da tradução: Silvana Cobucci Leite. 2. ed. São Paulo: Martins Fontes, 2008.

BOBBIO, Norberto; MATTEUCCI, Nicola; PASQUINO, Gianfranco. Dicionário de política. 13. ed. Brasília: UnB, 2007. v. 1.

BOGDAN, Michael. Private international law as component of the law of the forum: general course. Recueil des Cours, Académie de Droit International de la Haye, v. 348, p. 9-252, 2011.

BOUZA VIDAL, Nuria. Problemas de adaptación en derecho internacional privado e interregional. Madrid: Editorial Tecnos, 1977.

BRENA SESMA, Ingrid. La gestación subrogada: ¿una nueva figura del derecho de familia? In: BRENA SESMA, Ingrid. (Coord.). Reproducción asistida. México: UNAM, Instituto de Investigaciones Jurídicas, 2012. p. 139-161. (Serie Estudios Jurídicos, 206). Disponível em: http://biblio.juridicas.unam.mx/libros/7/3155/10.pdf. Acesso em: 09 jul. 2019.

BRITTO, Carlos Ayres. Teoria da Constituição. Rio de Janeiro: Forense, 2003.

BROCHER, Charles. Théorie du droit international privé (troisième article). Revue de Droit International et de Législation Comparée, Paris, v. 4, p. 189-220, 1872.

BRUGGER, Winfried. A cruz antropológica da decisão na política e no direito. Tradução: Ana Paula Barbosa-Fohmann e Leandro Freire M. Cavalcante. São Paulo, Saraiva, 2016. E-book.

BUCHER, Andreas. La dimension sociale du droit internationale privé. Recueil des Cours, Académie de Droit International de La Haye, v. 341, 9-526, 2009. 
BUCHER, Andreas. La famille en droit international privé. Recueil des Cours, Académie de Droit International de La Haye, v. 283, p. 9-186, 2000.

BUCHER, Andreas. L'ordre public et le but social des lois en droit international privé. Recueil des Cours, Académie de Droit International de La Haye, v. 239, p. 9-116, 1993.

BURUIANÃ, Monica-Elena. L'application de la loi étrangère en droit international privé. Thèse (Doctorat en Droit Privé) - École Doctorale, Université de Bordeaux, Bordeaux, 2016. Disponível em: https://tel.archives-ouvertes.fr/tel-01800429/document. Acesso em: 15 jul 2019.

CALVO CARAVACA, Alfonso-Luis; CARRASCOSA GONZÁLEZ, Javier. Derecho internacional privado y matrimonios entre personas del mismo sexo. Anales de Derecho, Universidad de Murcia, n. 23, p. 11-70, 2005. Disponível em: https://digitum.um.es/xmlui/bitstream/10201/11397/1/AD23\%202005\%20p\%201170.pdf. Acesso em: 06 ago. 2019).

CANOTILHO, José Joaquim Gomes. Direito constitucional e teoria da constituição. Coimbra: Almedina. 7. ed. 8. reimpr. Coimbra: Almedina, 2003.

CANOTILHO, José Joaquim Gomes. Estudo sobre direitos fundamentais. Coimbra: Coimbra Editora, 2004.

CANSACCHI, Giorgio. Le choix et l'adaptation de la règle étrangère dans les conflits de lois. Recueil des Cours, Académie de Droit International de La Haye, v. 83, p. 79-162, 1953.

CAPITANI, Amandine. Le droit à l'information et le droit à la participation en matière environnementale, une avancée constitutionnelle? Disponível em: http://www.droitconstitutionnel.org/congresmtp/textes2/CAPITANI.pdf. Acesso em: 02 jun. 2019.

CAPPELLETTI, Mauro. O controle judicial de constitucionalidade das leis no direito comparado. Tradução: Aroldo Plínio Gonçalves. 2. ed. Porto Alegre: Sergio Antonio Fabris, 1992.

CARVALHO, Márcia Dometila Lima de. Fundamentação constitucional do direito penal: crimes econômicos: responsabilidade penal das pessoas jurídicas: legalidade, culpabilidade e justiça social. Porto Alegre: Sergio Antonio Fabris, 1992.

CARVALHO, Osvaldo Ferreira de; COSTA, Eliane Romeiro. O princípio da proibição de retrocesso social no atual marco jurídico-constitucional brasileiro. Revista de Direito Público, Instituto Brasiliense de Direito Público (IDP), v. 7, n. 34, p. 7-40, jul./ago. 2010.

CASSETTARI, Christiano. Multiparentalidade e parentalidade socioafetiva: efeitos jurídicos. São Paulo. Atlas, 2014. 
CASTRO, Amilcar de. Da capacidade em direito internacional privado. Revista da Faculdade de Direito da Universidade de Minas Gerais, v. 4, p. 48-59, 1952. Disponível em: https://www.direito.ufmg.br/revista/index.php/revista/article/view/512/481. Acesso em: 28 dez. 2019.

CASTRO, Amílcar de. Direito internacional privado. 3. ed., aum. e corr. Rio de Janeiro: Forense, 1977.

CERQUEIRA, Gustavo. A conformidade do direito estrangeiro com a ordem constitucional e convencional do estado de origem: fundamentos e desafios do duplo controle no Brasil. Revista dos Tribunais, São Paulo, ano 106, v. 982, p. 237-282, ago. 2017.

CHAMBERLAND, Line; JOUVIN, Émilie; JULIEN, Danielle. Les familles recomposées homoparentales et hétéroparentales. Nouvelles Pratiques Sociales, v. 16, n. 1, p. 94-112, 2003. Disponível em: https://www.erudit.org/fr/revues/nps/2003-v16-n1nps742/009629ar.pdf. Acesso em: 20 ago. 2019.

CHAMBERS, David L. Polygamy and same-sex marriage. Hofstra Law Review, v. 26, No. 1, p. 53-84, Fall 1997. Disponível em: https://scholarlycommons.law.hofstra.edu/hlr/vol26/iss1/2/. Acesso em: 10 set. 2019.

COMPARATO, Fábio Konder. A afirmação histórica dos direitos humanos. 12. ed. São Paulo: Saraiva, 2019.

CORDEIRO, António Manuel da Rocha e Menezes. Da boa fé no direito civil. 6. reimpr. Coimbra: Almedina, 2015.

CORREIA, António Ferrer. Lições de direito internacional privado I. 9. reimp. da edição de outubro de 2000. Coimbra: Almedina, 2018.

COSTA, Dilvanir José da. A família nas Constituições. Revista de Informação Legislativa, Brasília, v. 43, n. 169, p. 13-19 jan./mar. 2006. Disponível em: http://www2.senado.leg.br/bdsf/bitstream/handle/id/92305/Costa\%20Dilvanir.pdf?sequenc $\mathrm{e}=6$. Acesso em: 01 jul. 2019.

DIAS, Maria Berenice. Manual de direito das famílias. 9. ed. rev., atual. e ampl., 4. tiragem. São Paulo: Revista dos Tribunais, 2013.

DÍAZ LABRANO, Roberto Ruiz. Friedrich Karl von Savigny e o direito internacional privado: vigência de sua doutrina. Tradução: Maria Laula Arnt. Revista de la Secretaría del Tribunal Permanente de Revisión, Asunción, año 1, n. 2, p. 247-270, 2013. Título original: Friedrich Karl von Savigny y el derecho internacional privado: vigencia de su doctrina. Disponível em: https://docplayer.com.br/39608937-Friedrich-karl-von-savigny-eo-direito-internacional-privado-vigencia-de-sua-doutrina.html. Acesso em: 11 set. 2019.

DINIZ, Maria Helena. Curso de direito civil brasileiro: direito de família. 30. ed. São Paulo: Saraiva, 2015. v. 5. 
DOLINGER, Jacob. Direito e amor e outros temas. Rio de Janeiro: Renovar, 2009.

DOLINGER, Jacob. Direito civil internacional: a família no direito internacional privado: casamento e divórcio no direito internacional privado. Rio de Janeiro: Renovar, 1997. v. 1, t. 1.

DOLINGER, Jacob. Direito internacional privado: parte geral. 11. ed. rev. e atual. e ampl. Rio de Janeiro: Forense, 2014.

DOLINGER, Jacob. Direito internacional privado: o princípio da proximidade e o futuro da humanidade. Revista de Direito Administrativo, Rio de Janeiro, v. 235, p. 139-146, jan./mar. $2004 . \quad$ Disponível em: http://bibliotecadigital.fgv.br/ojs/index.php/rda/article/view/45129/45051. Acesso em: 10 jun. 2018.

DOLINGER, Jacob. A evolução da ordem pública no direito internacional privado. Tese (Cátedra de Direito Internacional Privado) - Faculdade de Direito da Universidade Estadual do Rio de Janeiro, Rio de Janeiro, 1979.

DOLINGER, Jacob. A ordem pública internacional em seus diversos patamares. Revista dos Tribunais. São Paulo, v. 93, n. 828, p. 33-42, out. 2004.

DOLINGER, Jacob. Ordem pública mundial: ordem pública verdadeiramente internacional no direito internacional privado. Revista de Informação Legislativa, Brasília, v. 23, n. 90, p. 205-232, abr./jun. $1986 . \quad$ Disponível em: https://www2.senado.leg.br/bdsf/bitstream/handle/id/181712/000426674.pdf?sequence=3 \&isAllowed=y. Acesso em: $30 \mathrm{dez} .2019$.

DOLINGER, Jacob; TIBURCIO, Carmen. Direito internacional privado. 13. ed. rev., atual. e ampl. com a colaboração de Felipe Albuquerque. Rio de Janeiro: Forense, 2017.

ESBORRAZ, David Fabio. El concepto constitucional de familia en América Latina: tendencias y proyecciones. Revista de Derecho Privado, n. 29, p. 15-55, jul./dic. 2015. Disponível em: https://revistas.uexternado.edu.co/index.php/derpri/article/view/4323/4907. Acesso em: 10 set. 2019.

ESPÍNOLA, Eduardo; ESPÍNOLA FILHO, Eduardo. A Lei de Introdução ao Código Civil brasileiro: Dec.-Lei n. 4.657, de 4 de setembro de 1942, com as alterações da Lei n. 3.238, de $1^{\circ}$ de agosto de 1957, e leis posteriores comentada na ordem dos seus artigos. Atualizada por José da Silva Pacheco. 3. ed. Rio de Janeiro: Renovar, 1999. v. 1, arts. $1^{\text {o }}$ ao $7^{\circ}$.

FADLALLAH, Ibrahim. L'ordre public dans les sentences arbitrales. Recueil des Cours, Académie de Droit International de La Haye, v. 249, p. 369-430, 1994.

FARIAS, Cristiano Chaves de; ROSENVALD, Nelson. Direito das famílias. Rio de Janeiro: Lumen Juris, 2009. 
FAUVARQUE-COSSON Bénédicte. Droit comparé et droit international privé: la confrontation de deux logiques à travers l'exemple des droits fondamentaux. Revue Internationale de Droit Comparé, v. 52, n. 4, p. 797-818, oct./déc. 2000. Disponível em: https://www.persee.fr/doc/ridc_0035-3337_2000_num_52_4_18629. Acesso em: 06 jul. 2019.

FAVOREU, Louis. El bloque de la constitucionalidad. Revista del Centro de Estudios Constitucionales, n. 5, p. 45-68, enero/marzo, 1990. Disponível em: https://dialnet.unirioja.es/descarga/articulo/1049150.pdf. Acesso em: 20 jun. 2019.

FERRAZ, Anna Cândida da Cunha. Mutação, reforma e revisão das normas constitucionais. Revista de Direito Constitucional e Internacional, São Paulo, v. 5, p. 5-24, out./dez. 1993.

FERRAZ JÚNIOR, Tércio Sampaio. Introdução ao estudo do direito: técnica, decisão, dominação. 11. ed. São Paulo, Atlas, 2019.

FERREIRA FILHO, Manoel Gonçalves. Aspectos do direito constitucional contemporâneo. 3. ed. São Paulo: Saraiva, 2011. E-book.

FILOCRE, Lincoln D'Aquino. Revisita à ordem pública. Revista de Informação Legislativa, Brasília, DF, v. 46, n. 184, p. 132-147, out./dez. 2009.

FIORE, Pasquale. De l'ordre public en droit international privé. Revue de Droit International et de Legislation Comparée, 2ème série, v. 4, n. 6, p. 608-622, 1902. Disponível em: https://gallica.bnf.fr/ark:/12148/bpt6k6139112m/f724.item.r="Il\%20fait\%20en\%20outre\% 20remarquer". Acesso em: 16 mar. 2019.

FIORE, Pasquale (Rapporteur). De l'ordre public en droit international privé. Justitia et Pace Institut de Droit International, Session de Paris, 30 mars 1910. Disponível em: http://www.idi-iil.org/app/uploads/2017/06/1910_paris_02_fr.pdf. Acesso em: 16 mar. 2019.

FOSTER, John. La théorie anglaise du droit international privé. Recueil des Cours, Académie de Droit International de La Haye, v. 65, p. 395-560, 1938.

FOUILLET, Aurélien. L'esprit du jeu dans les sociétés postmodernes: anomies et socialités: bovarysme, mémoire et aventure. Paris: Université René Descartes - Paris V, 2012. Disponível em: https://tel.archives-ouvertes.fr/tel-00801205/document. Acesso em: 06 jun. 2019.

FRADERA, Véra Maria Jacob de. Aspectos problemáticos da utilização da arbitragem privada na solução de litígios relativos a direitos patrimoniais disponíveis: comentários à lei da arbitragem. In: MARQUES, Claudia Lima; ARAUJO, Nadia de (org.). O novo direito internacional: estudos em homenagem a Erick Jayme. Renovar. Rio de Janeiro, 2005. p. 403-422. 
FREUD, Sigmund. Totem e tabu: algumas concordâncias entre a vida psíquica dos homens primitivos e a dos neuróticos. Tradução: Paulo César de Souza. São Paulo: Penguin Classics, Companhia das Letras, 2013.

GAGLIANO, Pablo Stolze; PAMPLONA FILHO, Rodolfo. Novo curso de direito civil: direito de família. 9. ed. rev., atual. e ampl. São Paulo: Saraiva Jur, 2019. v. 6.

GAUDEMET-TALLON, Hélène. La désunion du couple en droit international privé. Recueil des Cours, Académie de Droit International de La Haye, v. 226, p. 9-280, 1991.

GAUDEMET-TALLON, Hélène. Le pluralisme en droit international privé: richesses et faiblesses (le funambule et l'arc-en-ciel): cours général. Recueil des Cours, Académie de Droit International de La Haye, v. 312, p. 9-488, 2005.

GIHL, Torsten. Lois politiques et droit international privé. Recueil des Cours, Académie de Droit International de La Haye, v. 83, p. 163-254, 1953.

GOLDSCHMIDT, Werner. Suma del derecho internacional privado. Buenos Aires: Ediciones Jurídicas Europa-América, 1958.

GOLDSTEIN, Gérald. La cohabitation hors mariage en droit international privé. Recueil des Cours, Académie de Droit International de La Haye, v. 320, p. 9-390, 2006.

GOMES, José Jairo. Lei de Introdução às Normas do Direito Brasileiro: LINDB. São Paulo: Atlas, 2012.

GONÇALVES, Anabela Susana de Sousa. Aspectos civis do rapto internacional de crianças: entre a convenção de Haia e o regulamento Bruxelas II bis. Cadernos de Dereito Actual, n. 3, p. 173-186, 2015.

GONÇALVES, Anabela Susana de Sousa. A deslocação ou retenção ilícitas de crianças no Regulamento n. 2201/2003 (Bruxelas II Bis). Cuadernos de Derecho Transnacional, v. 6, n. 1, p. 147-160, mar. 2014.

GONÇALVES, Luiz Carlos dos Santos. Mandados expressos de criminalização e a proteção dos direitos fundamentais na Constituição Brasileira de 1988. Belo Horizonte: Fórum, 2007.

GONZÁLEZ MARTÍN, Nuria. Modelos familiares ante el nuevo orden jurídico. In: Carbonell, José; CARBONELL, Miguel; GONZÁLEZ MARTÍN, Nuria. Las familias en el siglo XXI: una mirada desde el derecho. México: Universidad Nacional Autónoma de México (UNAN), Instituto de Investigaciones Jurídicas, 2012. Disponível em: https://archivos.juridicas.unam.mx/www/bjv/libros/7/3174/4.pdf. Acesso em: 12 ago. 2019.

GRAHAM-SIEGENTHALER, Barbara E. Principles of marriage recognition applied to same-sex marriage recognition in Switzerland and Europe. Creighton Law Review, v. 32, n. $1, \quad$ p. 121-146, 1999. Disponível em: https://dspace2.creighton.edu/xmlui/bitstream/handle/10504/40268/15_32CreightonLRev1 21(1998-1999).pdf;sequence=1. Acesso em: 09 jul. 2019. 
GRAMMATICAKI-ALEXIOU, Anastasia. Artificial reproduction technologies and conflict of laws: an initial approach. Louisiana Law Review, v. 60, No. 4, Conflict of laws, comparative law and civil law: a tribute to Symeon C. Symeonides, p. 1.112-1.121, Summer 2000. Disponível em https://digitalcommons.law.lsu.edu/cgi/viewcontent.cgi?article=5843\&context=lalrev. Acesso em: 30 dez. 2019.

GROENINGA, Giselle. Do interesse à criança ao melhor interesse da criança: contribuições da mediação interdisciplinar. Revista do Advogado, São Paulo, n. 62, p. 72 83, mar. 2001.

GUSMÃO, Paulo Dourado de. Introdução ao estudo do direito. 20. ed. Rio de Janeiro: Forense, 1997.

HEALY, Thomas H. Théorie générale de l'ordre public. Recueil des Cours, Académie de Droit International de La Haye, v. 9, p. 407-558, 1925.

HÉRITIER, Françoise. O eu, o outro e a intolerância. In: BARRET-DUCROCQ (Dir.). A intolerância: Foro Internacional sobre a Intolerância, Unesco, 27 de março de 1997, La Sorbonne, 28 de março de 1997. Tradução: Eloá Jacobina. Rio de Janeiro: Bertrand Brasil, 2000. p. 24-27.

HESSE Konrad. A força normativa da Constituição. Reimpressão. Tradução: Gilmar Ferreira Mendes. Porto Alegre. Sergio Antonio Fabris, 1991.

HIRONAKA, Giselda Maria Fernandes Novaes. Os contornos jurídicos da responsabilidade afetiva nas relações entre pais e filhos: além da obrigação legal de caráter material: além da obrigação legal de caráter material. Repertório IOB de jurisprudência: civil, processual, penal e comercial, v. 3, n. 18, 2. quinz. set. 2006. [Online].

HOLANDA JÚNIOR, Francisco Wilson Nogueira. Evitação e proibição do incesto: fatores psicobiológicos e culturais. Revista de Psicologia da USP, São Paulo, v. 28, n. 2, p. $287-$ 297, ago. 2017. Disponível em: http://www.scielo.br/scielo.php?script=sci_arttext\&pid=S0103-

$65642017000200287 \& \operatorname{lng}=$ pt\&nrm=iso. Acesso em: 18 set. 2019.

HUSSERL, Gerhart. Public policy and ordre public. Virginia Law Review, v. 25, No. 1, p. 37-67, Nov. 1938.

ISRAELI men could be jailed for refusing divorce: new directive from state prosecutor authorizes criminal charges against husbands who won't grant their wives religious divorce. The Times of Israel, 15 Nov. 2016. Disponível em: https://www.timesofisrael.com/israeli-men-who-refuse-divorce-could-face-jail/. Acesso em 15 dez. 2019.

ISSUES in jewish ethics: divorce. In: Jewish Virtual Library. Disponível em: https://www.jewishvirtuallibrary.org/divorce-in-judaism. Acesso em: 15 dez. 2019. 
JAYME, Erik. Le droit international privé du nouveau millénaire: la protection de la personne humaine face à la globalisation (conférence). Recueil des Cours, Académie de Droit International de La Haye, v. 282, p. 9-40, 2000.

JAYME, Erik. Identité culturelle et intégration: le droit international privé postmoderne. Recueil des Cours, Académie de Droit International de La Haye, v. 251, p. 9-268, 1995.

JAYME, Erik. Métodos para la concretización del orden público en el derecho internacional privado. Revista de la Facultad de Ciencias Jurídicas y Políticas, Caracas, Universidad Central de Venezuela, n. 82, p. 215-270, 1991.

JAYME, Erik. L'ordre public national et le droit international privé. In: Identité culturelle et intégration: le droit international privé postmoderne. Recueil des Cours, Académie de Droit International de La Haye, v. 251, p. 223-267, 1995.

JEWISH divorce 101: the basic procedure of the jewish divorce: the mutual agreement, the document, the ceremony, and the aftermath. Disponível em: https://www.chabad.org/library/article_cdo/aid/557906/jewish/Divorce-Basics.htm. Acesso em: 15 dez. 2019.

KANT, Immanuel. A metafísica dos costumes. Tradução: Edson Bini. Bauru: Edipro, 2003.

KELSEN, Hans. Teoria geral do direito e do Estado. Tradução: Luís Carlos Borges. 3. ed. 2. tiragem. São Paulo: Martins Fontes. 2000.

KLARMAN, Michael. Courts, social change, and political backlash. Philip A. Hart Memorial Lecture. 2. Washington, DC: Georgetown University Law Center, 2011. Disponível em: https://scholarship.law.georgetown.edu/hartlecture/2. Acesso em: $15 \mathrm{dez}$. 2019.

KNOEPFLER, François. Le droit international privé: froideur mécanique ou justice casuistique. In: CONFERENCES UNIVERSITAIRES DE NEUCHATEL, Neuchâtel, 1976. Neuchâtel: Université de Neuchâtel, Faculté de Droit et des Sciences Économiques, 1976.

LAGARDE, Paul. La méthode de la reconnaissance est-elle l'avenir du droit international privé?: Conférence inaugurale, session de droit international privé. Recueil des Cours, Académie de Droit International de La Haye, v. 371, p. 9-42, 2014.

LAGARDE, Paul. Convenção de 13 de janeiro de 2000 relativa à Proteção Internacional de Adultos: relatório explicativo. Haia: Conferência da Haia de Direito Internacional Privado, 2017. p. 9-22. Disponível em: https://assets.hcch.net/docs/669b8095-0c39-4d10a55b-792ef8e883cc.pdf. Acesso em: 12 jun. 2019.

LALIVE Pierre. Tendances et méthodes en droit international privé: cours général. Recueil des Cours, Académie de Droit International de La Haye, v. 155, p. 8-425, 1977.

LALLEMAND, Suzanne. Cahiers d'Études Africaines, v. 29, n. 114, 1989. Rivages I. p. 301-303. Resenha da obra: FAINZANG, Sylvie; JOURNET, Odile. La femme de mon mari: anthropologie du mariage polygamique en Afrique et en France. Paris: l'Harmattan, 1988. Disponível em: https://www.persee.fr/doc/cea_00080055_1989_num_29_114_1650_t1_0301_0000_3. Acesso em: 18 ago. 2019. 
LÉVI-STRAUSS, Claude. As estruturas elementares do parentesco. Tradução: Mariano Ferreira. 2. ed. Petrópolis: Vozes, 1982. p. 50. Disponível em: https://classicos12011.files.wordpress.com/2011/03/lc3a9vi-strauss-claude-as-estruturaselementares-do-parentesco.pdf. Acesso em: 20 set. 2019.

LIMA, Alberto Jorge Correia de Barros. Direito penal constitucional: a imposição dos princípios constitucionais penais. São Paulo: Saraiva, 2012. E-book.

LÔBO, Paulo. Direito civil: famílias. 9. ed. São Paulo: Saraiva, 2019. v. 5.

LÔBO, Paulo. Princípio da solidariedade familiar. Revista Jus Navigandi, Teresina, ano 18, n. 3.759, 16 out. 2013. Disponível em: https://jus.com.br/artigos/25364/principio-dasolidariedade-familiar. Acesso em: 15 dez. 2019.

LOPES, Ana Maria D’Ávila. A era dos direitos de Bobbio: entre a historicidade e a atemporalidade. Revista de Informação Legislativa, Brasília, v. 48, n. 192, p. 7-19, out./dez. 2011. Disponível em: https://www12.senado.leg.br/ril/edicoes/48/192/ril_v48_n192_p7.pdf. Acesso em: 20 jun. 2019.

MACHADO, João Baptista. Lições de direito internacional privado. 3. ed. actual. reimpr. Coimbra: Almedina, 2015.

MACHADO, João Baptista. Problemas na aplicação do direito estrangeiro: adaptação e substituição. Boletim da Faculdade de Direito, Universidade de Coimbra, v. 36, p. 327$351,1960$.

MALUF, Adriana Caldas do Rego Freitas Dabus. Direito das famílias: amor e bioética. Rio de Janeiro. Elsevier, 2012.

MANCINI, Pasquale Stanislao. Della nazionalità come fondamento del dritto delle genti. Torino: Tipografia Eredi Botta, 1851. Disponível em: https://books.google.com.br/books?id=dHC445QKgSQC\&printsec $=$ frontcover\&redir_esc $=$ $\mathrm{y} \# \mathrm{v}=$ onepage $\& \mathrm{q} \& \mathrm{f}=$ false. Acesso em: 05 set. 2019.

MARIN, Jean-Claude. Le juge est-il toujours la bouche de la loi? Disponível em: http://www.paris.notaires.fr/sites/default/files/club_du_chatelet_novembre_2011_discours _de_jean-claude_marin_le_juge_est-il_toujours_la_bouche_de_la_loi_discours.pdf. Acesso em: 19 jun. 2018.

MARTINS-COSTA, Judith. A boa-fé no direito privado: critérios para a sua aplicação. 2. ed., 2. tiragem. São Paulo: Saraiva, 2018. E-book.

MATIA PORTILLA, Francisco Javier. ¿Resulta oportuno dar un tratamiento jurídico a la gestación subrogada en nuestro país? Revista de Derecho Político, Universidad Nacional de Educación a Distancia (UNED), n. 105, p. 81-125, mayo-agosto 2019.

MATOS, Ana Carla Harmatiuk. Direito das famílias e proibição do retrocesso social. In: PEREIRA, Rodrigo de Cunha (coord.). Tratado de direito das famílias. 3. ed. Belo Horizonte: IBDFAM, 2019. p. 137-154. 
MAUÉS, Antonio Moreira. Supralegalidade dos tratados internacionais de direitos humanos e interpretação constitucional. SUR, Revista Internacional de Direitos Humanos, v. 10, n. 18, p. $215-235$, jun. 2013. Disponível em: https://sur.conectas.org/wpcontent/uploads/2017/11/sur18-port-antonio-moreira-maues.pdf. Acesso em: 20 jun. 2019.

MELlO, Celso Antônio Bandeira de. Conteúdo jurídico do princípio da igualdade. 3. ed. atual. 17. tiragem. São Paulo: Malheiros, 1999.

MENDES, Gilmar Ferreira. Direitos fundamentais e controle de constitucionalidade: estudos de direito constitucional. 3. ed., 4. tiragem. São Paulo: Saraiva, 2009.

MENDES, Gilmar Ferreira; BRANCO, Paulo Gustavo Gonet. Curso de direito constitucional. 11. ed. São Paulo: Saraiva, 2016.

MIRANDA, Jorge. Manual de direito constitucional: inconstitucionalidade e garantia da Constituição. 3. ed. rev. e actual. Coimbra: Coimbra Editora, 2008. v. 6.

MNDAWENI, Cedric B. Limping marriages in the new South Africa? Comparative and International Law Journal of Southern Africa, v. 24, n. 2, p. 215-225, July 1991. Disponível em: https://journals.co.za/docserver/fulltext/cilsa/24/2/559.pdf?expires=1568040525\&id=id\&a c cname $=$ guest $\&$ checksum $=4$ DD67562398476AB3760DF6E3BD3A168. Acesso em: 13 ago. 2019.

MOHAMED SALAH, Mohamed Mahmoud. Loi d'autonomie et méthodes de protection de la partie faible en droit international privé. Recueil des Cours, Académie de Droit International de La Haye, v. 315, p. 141-264, 2005.

MONACO Gustavo Ferraz de Campos. Conflitos de leis no espaço e lacunas (inter)sistêmicas. São Paulo: Quartier Latin, 2019.

MONACO, Gustavo Ferraz de Campos. Controle de constitucionalidade da lei estrangeira. São Paulo: Quartier Latin, 2013.

MONACO, Gustavo Ferraz de Campos. Direitos da criança e adoção internacional. São Paulo: Revista dos Tribunais, 2002.

MONACO, Gustavo Ferraz de Campos. A exceção de ordem pública internacional. Revista da Faculdade de Direito, Universidade de São Paulo, São Paulo, v. 114, 2019. [No prelo].

MONACO, Gustavo Ferraz de Campos. Motivação interna da decisão de adotar: adoção por casais e por pessoas singulares. Revista Brasileira de Direito de Família, v. 4, n. 14, p. 43-50, jul./set. 2002.

MONACO, Gustavo Ferraz de Campos. O papel da Constituição brasileira e das convenções em vigor para o Brasil no sistema de controle do direito estrangeiro. Revista dos Tribunais, v. 106, n. 985, p. 319-339, nov. 2017.

MONACO, Gustavo Ferraz de Campos. A proteção da criança no cenário internacional. Belo Horizonte. Del Rey. 2005. 
MONACO, Gustavo Ferraz de Campos. La place de la Constitution Brésilienne et des conventions liant le Brésil dans le système de contrôle du droit étranger. In: CERQUEIRA, Gustavo; NORD, Nicolas (Dirs.). Contrôle de constitutionnalité et de conventionalité du droit étranger: ètudes de droit international privé (Amérique Latine - États-Unis Europe). Paris: Société de Législation Comparée, 2017. p. 173-186. (Collection Colloques, v. 34).

MONACO, Gustavo Ferraz de Campos; JUBILUT, Liliana Lyra. Direito internacional privado. São Paulo: Saraiva. 2012.

MONTEIRO, Washington de Barros. Curso de direito civil: direito de família. 36. ed. São Paulo: Saraiva, 2001. v. 2.

MORAES, José Luiz Souza de. L'effet cliquet e o bloco de constitucionalidade: a influência da jurisprudência do Conselho Constitucional francês na proibição do retrocesso dos direitos fundamentais no Brasil. In: ALMEIDA, Fernando Menezes de; ZAGO, Marina Fontão (Coords.). Direito público francês: temas fundamentais. São Paulo: Quartier Latin, 2018. p. 165-178.

MORAES, José Luiz Souza de. Uniões entre pessoas do mesmo gênero no direito internacional privado. Dissertação (Mestrado) - Faculdade de Direito da Universidade de São Paulo, São Paulo, 2016.

MORAES, José Luiz Souza de. Uniões entre pessoas do mesmo sexo, a ordem pública brasileira e o direito internacional privado. In: MONACO, Gustavo Ferraz de Campos; FULCHIRON, Hugues (org.). Famílias internacionais: seus direitos, seus deveres. São Paulo: Intelecto Editora, 2016. p. 133-168.

MORAES, José Luiz Souza de. Videoconferência como instrumento de garantia ao melhor interesse da criança na cooperação internacional da convenção sobre os aspectos civis do rapto (sequestro) internacional de crianças. In: CONGRESSO INTERNACIONAL DIREITO DA LUSOFONIA, 5., 2018, Minho, Portugal. Direito na lusofonia: direito e novas tecnologias. Organização: Maria Clara Calheiros, Mário Ferreira Monte, Maria Assunção Vale Pereira, Anabela Gonçalves. Braga: Escola de Direito da Universidade do Minho, 2018. p. 229-239.

MORELLI, Gaetano Elementi di diritto internazionale privato italiano. 11. ed. Napoli: Jovene, 1982.

MOULAY RCHID, Abderrazak. Les droits de l'enfant dans les conventions internationales et les solutions retenues dans les pays arabo-musulmans. Recueil des Cours, Académie de Droit International de La Haye, v. 268, p. 9-290, 1997.

MURPHY, Kent. The traditional view of public policy and ordre public in private international law. Georgia Journal of International and Comparative Law, v. 11, n. 3, p. 591-615, 1981. Disponível em: https://digitalcommons.law.uga.edu/cgi/viewcontent.cgi?article=1964\&context=gjicl. Acesso em: 06 jun. 2018. 
NAJURIETA, María Susana. L'adoption internationale des mineurs et les droits de l'enfant. Recueil des Cours, Académie de Droit International de La Haye, v. 376, p. 199494, 2014.

NASCIMENTO, Cristine Emily Santos. O idoso no sistema internacional de proteção aos direitos humanos. Disponível em: http://www.editoramagister.com/doutrina_27075299_O_IDOSO_NO_SISTEMA_INTER NACIONAL_DE_PROTECAO_AOS_DIREITOS_HUMANOS.aspx>. Acesso em: 02 jul. 2019.

NIETZCHE, Friedrich. A genealogia da moral. Tradução: Antonio Carlos Braga. São Paulo: Editora Escala, 2013.

NORD, Nicolas. Ordre public et lois de police en droit international privé. These (Doctorat en Droit) - Faculté de Droit, de Sciences Politiques et de Gestion, Université Robert Schuman Strasbourg III, Strasbourg, 2003. Disponível em: http://cdpf.unistra.fr/fileadmin/upload/CDPF/theses_memoires_et_rapports/ordre_public_e t_lois_de_police.pdf. Acesso em: 10 set. 2019.

OLIVA, Thiago Dias. O discurso de ódio contra as minorias sexuais e os limites da liberdade de expressão no Brasil. Dissertação (Mestrado em Diretos Humanos) Faculdade de Direito da Universidade de São Paulo, São Paulo, 2015. Disponível em: http://www.teses.usp.br/teses/disponiveis/2/2140/tde-14122015-093950/pt-br.php). Acesso em: 30 jun. 2019.

OLIVEIRA, Adriano Saldanha Gomes de. Direito internacional privado e direito à filiação. Rio de Janeiro: Lumen Juris, 2010.

OLIVEIRA, Carolina Lopes de. Saber ou não saber, eis a nova questão: o direito à identidade genética e o direito ao anonimato do doador nas inseminações artificiais heterólogas. Revista da Faculdade de Direito da Universidade Federal de Minas Gerais, n. 68, p. 221-247, jan./jun. 2016.

OVERBECK, Alfred Eugène von. Divers aspects de l'unification du droit international privé spécialement en matière de successions. Recueil des Cours, Académie de Droit International de La Haye, v. 104, p. 529-634, 1961.

PARRA-ARANGUREN, Gonzalo. General course of private international law: selected problems. Recueil des Cours, Académie de Droit International de La Haye, v. 210, p. 9224, 1988.

PEREIRA, Caio Mário da Silva. Instituições de direito civil: direito de família. 22. ed. Rio de Janeiro. Forense. 2014. v. 5.

PEREIRA, Rodrigo da Cunha. O perverso fetichismo da lei e suas consequências no direito familiar. Disponível em: http://www.ibdfam.org.br/artigos/1356/O+perverso+fetichismo+da+lei+e+suas+consequ\% C3\%AAncias+no+direito+familiar\%22. Acesso em: 15 set. 2019. 
PEREIRA, Tânia da Silva (coord.). O melhor interesse da criança: um debate interdisciplinar. Rio de Janeiro: Renovar, 2000.

PERELMAN, Chaïm. Ética e direito. Tradução: Maria Ermantina de Almeida Prado Galvão. 2. ed. São Paulo: Martins Fontes, 2005.

PÉREZ-VERA, Elisa. Informe explicativo del Convenio sobre los Aspectos Civiles de la Sustracción Internacional de Menores. La Haya: Conferencia de La Haya de Derecho Internacional Privado, 1982. Disponível em: https://assets.hcch.net/upload/expl28s.pdf. Acesso em: 09 dez. 2019.

PETRALIA, Valentina. Ricongiungimento familiare $e$ matrimonio poligamico: il riconoscimento di valori giuridici stranieri e la tutela delle posizioni deboli. Università di Catania [Online] Working Paper, n. 49, Febbraio, 2013. Disponível em: http://www.cde.unict.it/sites/default/files/Quaderno\%20europeo_49_febbraio_2013.pdf. Acesso em: 19 jul. 2019.

PHILIPPE, Antoine. The complexities of nuptiality: from early female union to male polygamy in Africa. In: CASELLI, G.; VALLIN, J.; WUNSCH, G. (Eds.). Demography: analysis and synthesis, a treatise in population studies. Amsterdam: Elsevier Academic Press, 2006. v. 1, cap. 27, p. 355-371.

PILLET, Antoine. La théorie générale des droits acquis. Recueil des Cours, Académie de Droit International de La Haye, v. 8, p. 489-538, 1925.

PINHEIRO, Luís de Lima. Direito internacional privado: introdução e direito de conflito: parte geral. 3. ed. refundida. Coimbra. Almedina. 2014. v. 1.

PINHEIRO, Maria Cláudia Bucchianeri. A Constituição de Weimar e os direitos fundamentais sociais: a preponderância da Constituição da República Alemã de 1919 na inauguração do constitucionalismo social à luz da Constituição Mexicana de 1917. Revista de Informação Legislativa, Brasília, DF, v. 43, n. 169, p. 101-126, jan./mar. 2006.

PIOVESAN, Flávia. A Constituição de 1988 e os tratados internacionais de proteção dos direitos humanos. Revista da Procuradoria Geral do Estado de São Paulo, n. 47/48, p. 95114, jan./dez. 1997. Disponível em: http://www.pge.sp.gov.br/centrodeestudos/revistaspge/revista3/rev6.htm. Acesso em: 19 jun. 2019.

PIOVESAN, Flávia. Direitos humanos e o direito constitucional internacional. 4. ed. rev., ampl. e atual. São Paulo: Max Limonad, 2000.

PIOVESAN, Flavia. Proteção judicial contra omissões legislativas: ação direta de inconstitucionalidade por omissão e mandado de injunção. São Paulo: Revista dos Tribunais, 1995.

PONZONI, Laura de Toledo. Famílias simultâneas: união estável e concubinato. IBDFAM, 27 out. 2008.2 Disponível em: http://ibdfam.org.br/artigos/461/Fam\%C3\%ADlias+Simult\%C3\%A2neas\%3A+Uniao+Est \% $3 \%$ A1 vel+e+Concubinato\%22. Acesso em: 09 dez. 2019. 
RAMOS, André de Carvalho. O casamento no direito internacional privado no Brasil. Revista do Instituto dos Advogados de São Paulo, São Paulo, v. 18, n. 35, p. 165-190, jan./jun. 2015.

RAMOS, José Nabantino. Bigamia. In: FRANCO, Alberto Silva; NUCCI, Guilherme de Souza (org.). Direito penal. São Paulo: Revista dos Tribunais, 2010. v. 6, Parte especial II, p. 533-543. (Doutrinas Essenciais). [Online].

RAMOS, Paulo Roberto Barbosa. A proteção constitucional da pessoa idosa. Revista de Direito Constitucional e Internacional, São Paulo, Revista dos Tribunais, v. 11, n. 45, p. 157-174, out./dez. 2003.

RAMOS, Rui Manuel Gens de Moura. Direito internacional privado e Constituição: introdução a uma análise das suas relações. 3. reimpr. Coimbra: Coimbra Editora, 1994.

RAMOS, Rui Manuel Gens de Moura. O direito internacional privado da família nos inícios do século XXI: uma perspectiva europeia. In: OLIVEIRA, Guilherme (coord.). Textos de direito de família para Francisco Pereira Coelho. Coimbra: Imprensa da Universidade de Coimbra, 2016. p. 367-427.

REALE, Miguel. Filosofia do direito. 20. ed. 16. tiragem. São Paulo: Saraiva, 2017.

REALE, Miguel. Lições preliminares de direito. 27. ed. 8. tiragem. São Paulo, 2009.

REIS, Gabriel Valente dos. Por uma análise cosmopolitada determinação da lei aplicável. 2012. 128 p. Dissertação (Mestrado) - Faculdade de Direito da Universidade de São Paulo, São Paulo, 2012. Disponível em: https://www.teses.usp.br/teses/disponiveis/2/2135/tde22042013-114640/publico/Gabriel_Valente_dos_Reis.pdf. Acesso em: 10 dez. 2019.

RENCHON, Jean-Louis. Parente sociale et adoption homosexuelle: quel choix politique? Revue Générale de Droit, Montreal, Wilson \& Lafleur, v. 35, n. 1, p. 129-159, 2005.

RIDEAU, Joël. Le rôle de l'Union européenne en matière de protection des droits de l'homme. Recueil des Cours, Académie de Droit International de La Haye, v. 265, p. 9480, 1997.

RIGAUX, François. A lei dos juízes. Tradução: Edmir Missio. São Paulo: Martins Fontes, 2000.

RIGAUX, François. Les situations juridiques individuelles dans un système de relativité générale: cours générale de droit international privé. Recueil des Cours, Académie de Droit International de La Haye, v. 213, p. 9-407, 1989.

RODAS, João Grandino. Jus cogens em direito internacional. Revista da Faculdade de Direito, Universidade de São Paulo, v. 69, n. 2, p. 125-136, 1974.

RODRIGUES, Dárcio Roberto Martins. Aspectos de interesse atual do matrimônio romano. Revista da Faculdade de Direito, Universidade São Paulo, v. 93, p. 81-107, jan./dez. $1998 . \quad$ Disponível em: http://www.revistas.usp.br/rfdusp/article/viewFile/67400/70010. Acesso em: 11 jul. 2019. 
ROTONDANO, Ricardo Oliveira. Cultura e ética na formação familiar: a poligamia e a sua repressão no ocidente. Revista de Bioética y Derecho, Barcelona, Universitat de Barcelona, n. 38, p. 87-99, 2016. Disponível em: http://scielo.isciii.es/pdf/bioetica/n38/articulo5.pdf. Acesso em: 18 ago. 2019.

RUGGIERO, Roberto. Instituições de direito civil: direito de família, direitos reais e posse. Tradução da 6. ed. italiana: Paolo Capitanio. Campinas. Bookseller. 1999. v. 2.

SALAMÉ, Georgette. Le devenir de la famille en droit international privé: une perspective postmoderne. Marseille: Presses Universitaires d'Aix-Marseille, 2006.

SANTOS, Antonio Marques. Estudos de direito internacional privado e direito processual civil internacional. Coimbra: Almedina, 1988.

SANTOS, Romualdo Baptista dos. A tutela jurídica da afetividade: os laços humanos como valor jurídico na pós-modernidade Curitiba, Juruá, 2011.

SARLET, Ingo Wolfgang. Algumas notas em torno da relação entre o princípio da dignidade da pessoa humana e os direitos fundamentais na ordem constitucional brasileira. In: LEITE, George Salomão (org.). Dos princípios constitucionais: considerações em torno das normas principiológicas da constituição. São Paulo: Malheiros, 2003. p. 198-236.

SARLET, Ingo Wolfgang. A eficácia dos direitos fundamentais. 6. ed. Porto Alegre: Livraria do Advogado, 2006.

SARLET, Ingo Wolfgang; MARINONI, Luiz Guilherme; MITIDIERO, Daniel Francisco. Curso de direito constitucional. 5. ed., rev. e atual. São Paulo: Saraiva, 2016.

SARMENTO, Daniel. Direitos fundamentais e relações privadas. 2. ed. Rio de Janeiro: Lumen Juris, 2006.

SARMENTO, Daniel. A normatividade da Constituição e a constitucionalização do direito privado. Revista da EMERJ, v. 6, n. 23, p. 272-279, jan./jun. 2003.

SARTORI, Giana Lisa Zanardo. Reprodução humana assistida: um direito fundamental? Curitiba: Appris, 2015. E-book.

SAVIGNY, Friedrich Carl von. Sistema do direito romano atual. Livro III: Domínio das regras do direito sobre as relações jurídicas, Capítulo I: Limites locais do domínio das regras do direito sobre as relações jurídicas. Tradução: Ciro Mioranza. Ijuí: Unijuí, 2004.

SCHEUERMAN, William. Globalization. In: ZALTA, Edward N. (ed.). The Stanford Encyclopedia of Philosophy. Winter 2018 Edition. Disponível em: https://plato.stanford.edu/archives/win2018/entries/globalization/. Acesso em: 02 nov. 2019.

SCHOUERI, Luís Eduardo. O princípio do não retrocesso como nova perspectiva à denúncia de acordos de bitributação. Revista Direito Tributário Atual, São Paulo, Dialética, n. 29, p. 237-249, jan./jun. 2013. 
SIEGEL. Reva B. Same-sex marriage and backlash: constitutionalism through the lens of consensus and conflict. Max Weber Lexture Series. European University Institute. Max Weber Lecture No. 2016/04. Disponível em: https://cadmus.eui.eu/bitstream/handle/1814/41324/MWP_LS_2016_04.pdf?sequence=1\& isAllowed=y. Acesso em: 15 dez. 2019.

SILVA, José Afonso da. Aplicabilidade das normas constitucionais. 6. ed. São Paulo: Malheiros, 2002.

SILVA, José Afonso da. Comentário contextual à Constituição. 6. ed. atual. até a Emenda Constitucional 57, de 18.12.2008. São Paulo, Malheiros, 2009.

SILVA, Luis Antonio da Gama e. A ordem pública em direito internacional privado. Tese (Livre Docência) - Faculdade de Direito da Universidade de São Paulo, São Paulo, 1944.

SILVA, Virgílio Afonso da. A constitucionalização do direito: os direitos fundamentais nas relações entre particulares. São Paulo: Malheiros, 2005.

SILVA, Virgílio Afonso da. Interpretação conforme a Constituição. Revista Direito GV, v. 2, n. 1, p. 191-210, jan./jun. 2006.

SIMÃO, José Fernando. Casamento avuncular homoafetivo?: casamentos entre tios e sobrinhos. Carta Forense, São Paulo, 04 nov. 2013. Disponível em: http://www.cartaforense.com.br/conteudo/colunas/casamento-avuncular-homoafetivo-casamentos-entre-tios-e-sobrinhos/12387. Acesso em: 09 dez. 2019.

SIMÃO, José Fernando. O ensino do direito de família: um paradoxo a ser superado. Boletim IBDFAM, São Paulo, v. 12, n. 76, p. 7-8, set./out. 2012.

STIEFELMAN, Ilan. Guet: divórcio judaico é importante? Disponível em: https://pt.chabad.org/library/article_cdo/aid/3817715/jewish/Guet-Divrcio-JudaicoImportante.htm. Acesso em: 15 dez. 2019.

STORY, Joseph. Commentaries on the conflict of laws, foreign and domestic, in regard to contracts, rights, and remedies, and especially in regard to marriages, divorces, wills, successions, and judgments. 4th ed. rev. corr. e aum. Boston: Little, Brown and Company, 1852. Disponível em: http://www.unz.com/print/StoryJoseph-1834n02. Acesso em: 15 jul. 2019.

STRENGER, Irineu. O direito internacional na Constituição. In: BAPTISTA, Luiz Olavo; MAZZUOLI, Valerio de Oliveira (org.). Direito internacional. São Paulo: Revista dos Tribunais, 2012. v. 1, p. 1.051-1.054. (Doutrinas Essenciais). [Online].

STRENGER, Irineu. Direito internacional privado. 5. ed. São Paulo: LTr, 2003.

TARTUCE, Flávio. Direito civil: direito de família. 12. ed. rev., atual. e ampl. Rio de Janeiro: Forense, 2017. v. 5.

TARTUCE Flávio. $O$ divórcio unilateral ou impositivo. Disponível em: http://www.flaviotartuce.adv.br/. Acesso em: 08 set. 2019. 
TENÓRIO, Oscar. Direito internacional privado. 8. ed. Rio de Janeiro: Freitas Bastos, 1965. v. 1.

TOLEDO, Francisco de Assis. Princípios básicos de direito penal. 5. ed. São Paulo: Saraiva, 1994.

TORRES PEREA, José Manuel de. Tratamiento del interés del menor en el derecho alemán. Anuario de Derecho Civil, Madrid, v. 59, n. 2, p. 675-742, abr./jun. 2006.

UBERTAZZI, Giovanni Maria. Règles de non-discrimination et droit international privé. Recueil des Cours, Académie de Droit International de La Haye, v. 157, p. 333-414, 1977.

VALLADÃO, Haroldo. Direito internacional privado. 2. ed. Rio de Janeiro: Freitas Bastos, 1970.

VALLADÃO, Haroldo. O princípio da lei mais favorável no direito internacional privado. In: ORGANIZAÇÃO DOS ESTADOS AMERICANOS (OEA). Curso de derecho internacional. Washington, 1981. p. 522-560.

VAREILLES-SOMMIERES, Pascal. L'exception d'ordre public et la régularité substantielle internationale de la loi étrangère. Recueil des Cours, Académie de Droit International de La Haye, v. 371, p. 155-272, 2015.

VATTEL, Emer de. O direito das gentes. Prefácio e tradução: Vicente Marotta Rangel. Brasília: Editora Universidade de Brasília; Instituto de Pesquisa de Relações Internacionais, 2004. Disponível em: http://livros01.livrosgratis.com.br/al000223.pdf. Acesso em: 20 dez. 2019.

VELOSO, Zeno. Código Civil comentado: direito de família, alimentos, bem de família, união estável, tutela e curatela: artigos 1.694 a 1.783. Coordenação: Álvaro Villaça Azevedo. São Paulo: Atlas, 2003. v. 17.

VENOSA, Sílvio de Salvo. Código Civil interpretado. São Paulo: Atlas. 2010.

VENOSA, Sílvio de Salvo. Direito civil: direito de família. 10. ed. São Paulo: Atlas, 2010. v. 6 .

VENOSA, Sílvio de Salvo. Direito civil: família e sucessões. 19. ed. São Paulo: Atlas, 2019. v. 5.

WELLER, Marc-Philippe. Do Estado para a pessoa: a tríade metodológica do direito internacional privado do nosso tempo. Tradução: Rui Pereira Dias. Boletim da Faculdade de Direito da Universidade de Coimbra, v. 94, n. 1, p. 361-402, jan./jun. 2018.

WODON, Quentin; TAVARES, Paula; MALE, Chata; LOUREIRO, André. 2018. Erradicando o casamento infantil, casamento na infância e adolescência: a educação das meninas e a legislação brasileira. Ending Child Marriage Notes Series. Washington, DC: The World Bank. http://documents.worldbank.org/curated/pt/657391558537190232/pdf/Child-MarriageGirls-Education-and-the-Law-in-Brazil.pdf. Acesso em: 10 ago. 2019. 